\title{
Model calculations of the age of firn air across the Antarctic continent
}

\author{
K. A. Kaspers ${ }^{1}$, R. S. W. van de Wal ${ }^{1}$, M. R. van den Broeke ${ }^{1}$, J. Schwander ${ }^{2}$, N. P. M. van Lipzig ${ }^{3}$, and \\ C. A. M. Brenninkmeijer ${ }^{4}$ \\ ${ }^{1}$ Inst. for Marine and Atmospheric research Utrecht, Utrecht Univ., Princetonplein 5, 3584 CC Utrecht, The Netherlands \\ ${ }^{2}$ Physics Institute, University of Bern, Switzerland \\ ${ }^{3}$ British Antarctic Survey, Cambridge, UK \\ ${ }^{4}$ Max Planck Institute for Chemistry, Mainz, Germany
}

Received: 15 December 2003 - Published in Atmos. Chem. Phys. Discuss.: 24 March 2004

Revised: 1 July 2004 - Accepted: 26 July 2004 - Published: 24 August 2004

\begin{abstract}
The age of firn air in Antarctica at pore close-off depth is only known for a few specific sites where firn air has been sampled for analyses. We present a model that calculates the age of firn air at pore close-off depth for the entire Antarctic continent. The model basically uses four meteorological parameters as input (surface temperature, pressure, accumulation rate and wind speed). Using parameterisations for surface snow density, pore close-off density and tortuosity, in combination with a density-depth model and data of a regional atmospheric climate model, distribution of pore close-off depth for the entire Antarctic continent is determined. The deepest pore close-off depth was found for the East Antarctic Plateau near $72^{\circ} \mathrm{E}, 82^{\circ} \mathrm{S}$, at $150 \pm 15 \mathrm{~m}(2 \sigma)$. A firn air diffusion model was applied to calculate the age of $\mathrm{CO}_{2}$ at pore close-off depth. The results predict that the oldest firn gas $\left(\mathrm{CO}_{2}\right.$ age $)$ is located between Dome Fuji, Dome Argos and Vostok at $82^{\circ} \mathrm{E}, 83^{\circ} \mathrm{S}$ being $156 \pm 22(1 \sigma)$ years old with an age distribution of 103 years. At this location an atmospheric trace gas record should be obtained. In this study we show that methyl chloride could be recorded with a predicted length of 187 years (mean age of methyl chloride) as an example for trace gas records at this location. The longest record currently available from firn air is derived at South Pole, being 80 years.

Sensitivity tests reveal that the locations with old firn air (East Antarctic Plateau) have an estimated uncertainty $(2 \sigma)$ for the Modelled mean $\mathrm{CO}_{2}$ age at pore close-off depth of $30 \%$ and of about $35 \%$ for locations with younger firn air (mean $\mathrm{CO}_{2}$ age typically 40 years). Comparing the modelled age of $\mathrm{CO}_{2}$ at pore close-off depth with directly determined ages at ten sites yielded a correlation coefficient of 0.90 and a slope close to 1 , suggesting a high level of confidence for the modelled results in spite of considerable remaining uncertainties.
\end{abstract}

Correspondence to: K. A. Kaspers

(k.a.kaspers@phys.uu.nl)

\section{Introduction}

Air trapped in the open pores of a firn layer is ideal to acquire temporal records of atmospheric composition over the past 20-150 years. The Antarctic firn layer is known as a porous, permeable layer of snow on top of the ice sheet, which is compressed by the overlaying snow pack. In Antarctica this firn layer is typically $50-150 \mathrm{~m}$ thick. Because of the porous structure of the firn layer, large firn air volumes can be sampled and a wide range of trace gas analyses become possible. The possibility to study a wide range of trace gases is the biggest advantage of firn air analyses over the analyses of air trapped in bubbles and therefore explains why we want to find the oldest firn air.

With a firn diffusion model (Schwander et al., 1993; Rommelaere et al., 1997; Trudinger et al., 1997) vertical concentration profiles measured in a firn layer can be translated to historical time series of a particular gas in the atmosphere. Using this method, Butler et al. (1999) obtained records for CFCs and chlorocarbons at South Pole station, Siple Dome and Tunu (Greenland). Brominated methanes were recorded by Sturges et al. (2001) in air sampled at Dronning Maud Land, Dome $\mathrm{C}$ and Berkner Island. Concentrations of $\mathrm{CO}_{2}$ and CFCs at Law Dome were measured by Trudinger et al. $(1997,2002)$; non-methane hydrocarbons (ethane, propane and acetylene) were measured by Kaspers et al. (2004) for Dronning Maud Land. All the locations of previous firn air analyses are shown in Fig. 1. In this paper, we combine the information available from these experiments to model the mean and effective age of $\mathrm{CO}_{2}$ at pore close-off depth (PCOD) in Antarctica. This enables us to predict where the greatest PCOD can be found, and what the corresponding age of $\mathrm{CO}_{2}$ at PCOD is and the modelled uncertainty of the age. 


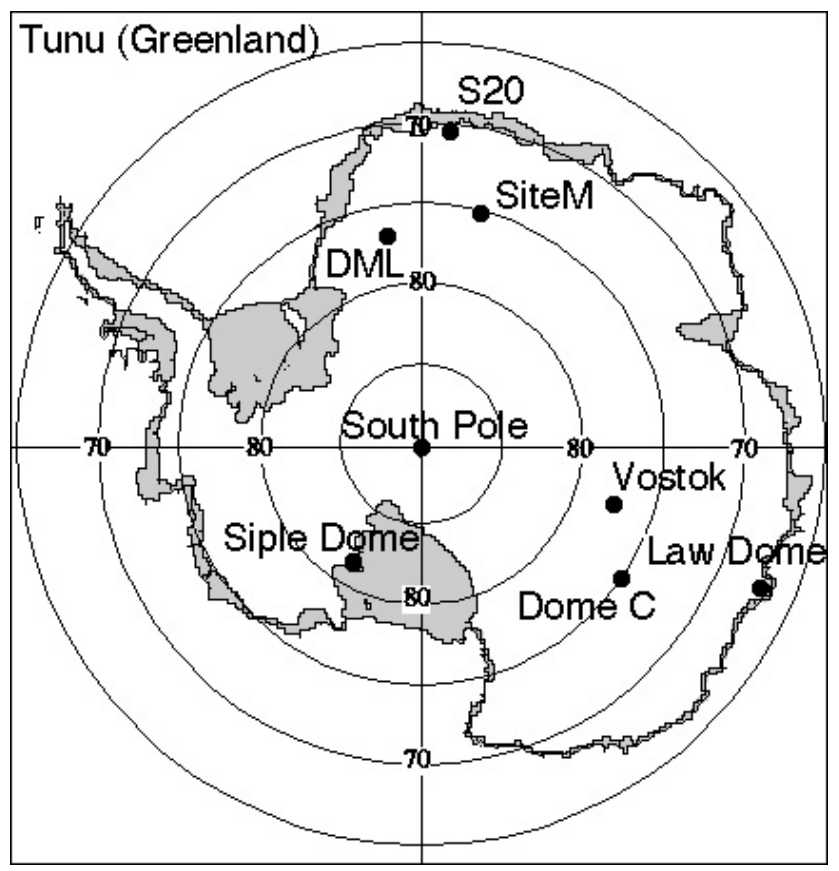

Fig. 1. Locations of the firn air sites used in this study. Elevation and meteorological conditions for these sites are given in Table 1.

The effective age depends on the atmospheric growth rate of $\mathrm{CO}_{2}$ in the atmosphere, other chemical species will therefore have an other age, and the mean age as defined by Trudinger et al. (2002) will therefore be slightly older. We would like to note that the PCOD in this study is defined as a specific depth based on a specific close off density value unlike a depth range as mentioned in some other studies. To account for the close off range we systematically varied the density profile $5 \%(2 \sigma)$ calculated from a density model in this study.

The following section explains how we use meteorological data to obtain the parameterisations for tortuosity, surface density and density at PCOD. We also briefly describe the diffusion model we have used. In Sect. 3, we present surface density and PCOD as well as the age of $\mathrm{CO}_{2}$ at PCOD for the entire Antarctic continent. This section also covers sensitivity experiments carried out to quantify the influence of uncertainties in the density and tortuosity profiles on the modelled firn $\mathrm{CO}_{2}$ age. We summarise our conclusions in Sect. 4.

\section{Methods}

To derive the age of firn air at PCOD one needs:

- The vertical velocity of air in the firn layer, derived from a firn air model (Sect. 2.1);

- The snow density profile $\rho_{(z)}$, including the surface density $\left(\rho_{0}\right)($ Sect. 2.2$)$;
- The density at PCOD $\left(\rho_{\mathrm{CO}}\right)($ Sect. 2.2);

- The tortuosity profile, which is a measure of the 3D pore structure (Sect. 2.2);

\subsection{Firn air model}

We applied the firn air diffusion model based on the concepts proposed by Schwander et al. $(1988,1993)$ to calculate the age of $\mathrm{CO}_{2}$ at PCOD. The model is described briefly here; a more detailed description is given in Kaspers et al. (2004). The model calculates the flux $j_{(z, t)}$ of air into the firn column, which depends on the flux of molecular diffusion $j_{\text {Diffusion }}$ and the flux due to gravity $j_{\text {gravity }}$ (Eq. 1).

$j_{z, t}=j_{\text {Diffusion }}+j_{\text {Gravity }}=-D_{z}\left(\frac{\partial C_{z, t}}{\partial z}+\frac{\mathrm{Mgz}}{\mathrm{RT}}\right)$.

Here, $D_{z}$ is the diffusion coefficient $\left(\mathrm{m}^{2} \mathrm{a}^{-1}\right), \partial C_{z, t} / \partial z$ is the variation of the time-dependent concentration $\left(\mathrm{C}_{z, t}\right)$ with depth $(z), \mathrm{Mgz} / \mathrm{RT}$ describes the settling due to gravity with $M$ the molecular mass (for $\mathrm{CO}_{2}, 44 \mathrm{~g} / \mathrm{mol}$ ), $g$ the gravitational constant, $R$ the gas constant and $T$ the annual mean surface temperature (K). The diffusion coefficient $D_{z}$ is described in more detail in Eqs. (2) and (3) (Schwander et al., 1993; Spahni et al., 2003).

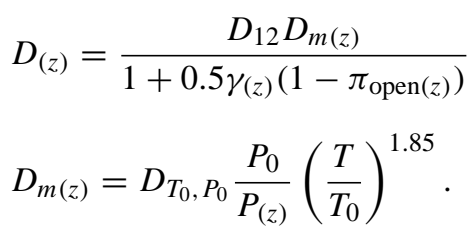

The diffusion coefficient $D_{(z)}$ is a function of the gas specific diffusion coefficient $D_{12}$, a correction term for atmospheric temperature and pressure $D_{m(z)}$, the open porosity $\pi_{\mathrm{open}(z)}$ and the tortuosity structure $\gamma_{(z)}$. Equation (3) describes the correction term for temperature and pressure. In this equation, $T_{0}$ and $P_{0}$ are $253 \mathrm{~K}$ and $1013 \mathrm{hPa}$, respectively.

The open porosity can be determined from a semiempirical relationship presented by Schwander (1989). In this relation, the open porosity is expressed inversely proportional to the density profile, which makes the density profile an important parameter in the diffusion model. Most of the firn air diffusion studies for specific sites apply a curve fit through a measured density profile (Schwander et al., 1993; Trudinger et al., 1997). To extrapolate results over all of Antarctica, we applied a firn density model. The choice of the density-depth model is described in detail in Sect. 2.2.

Another important site-specific parameter in the diffusion model is the tortuosity profile $\gamma_{(z)}$ (Spahni et al., 2003; Schwander et al., 1993). This profile is the main tuning parameter in the diffusion model and represents a correction term for the three-dimensional structure of the open porous firn. The tortuosity profile is described as

$\gamma_{z}=\gamma_{a}+\left(1-\gamma_{a}\right)\left(\pi_{\mathrm{open}(z)}\right)^{-\gamma_{b}}$. 

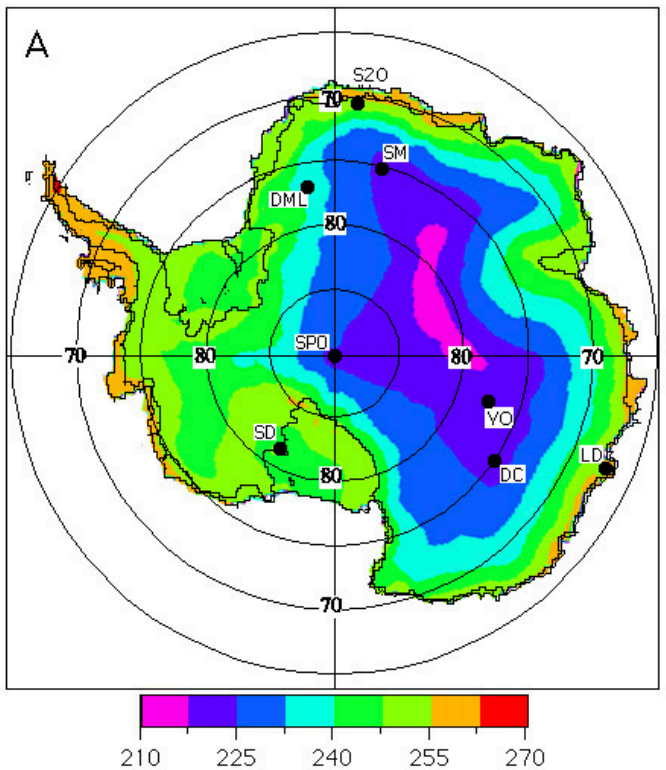

Surface temperature $(\mathrm{K})$

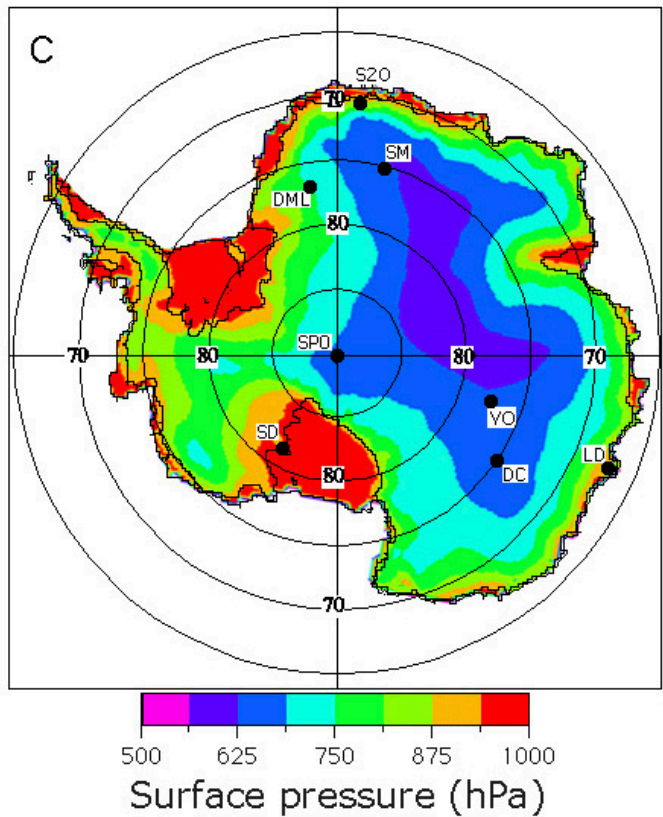

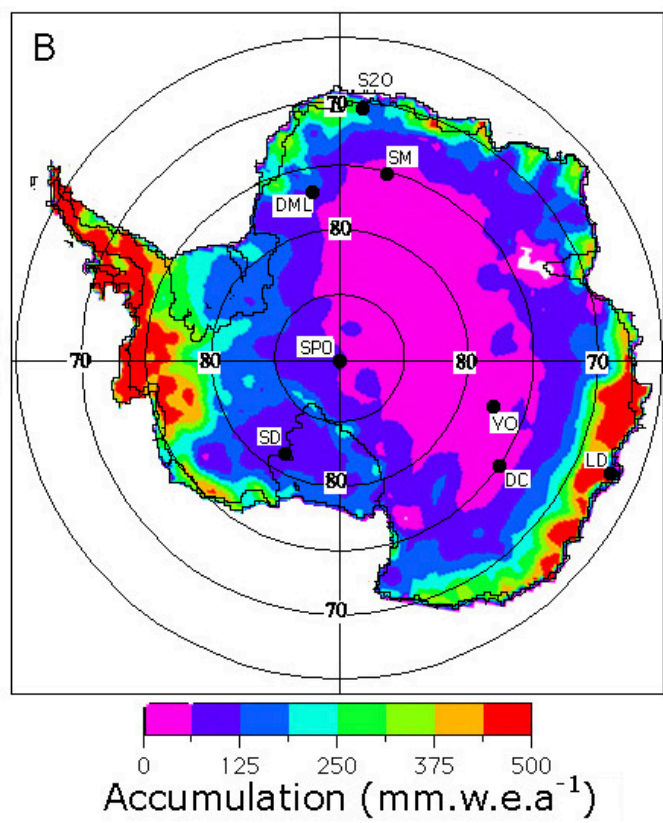

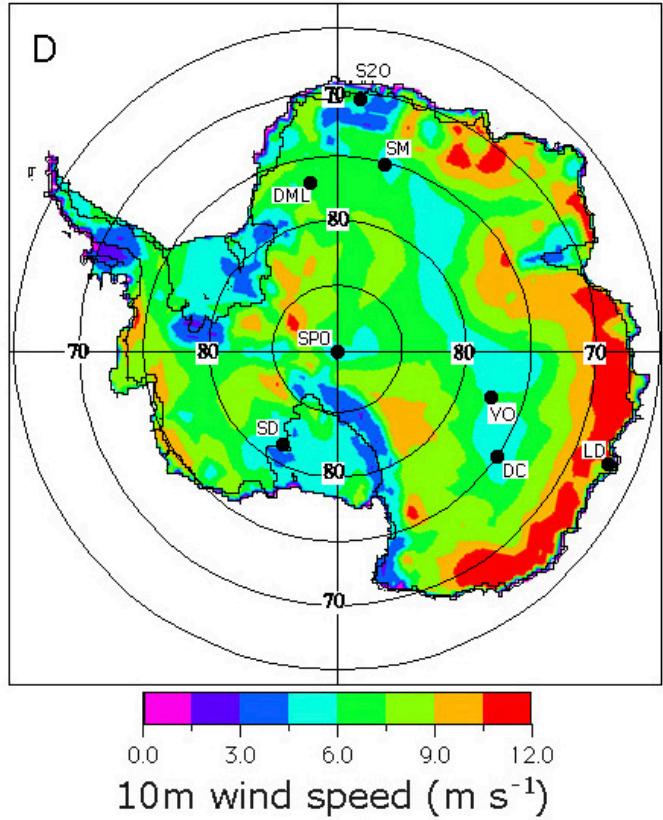

Fig. 2. Input parameters derived from the Regional Atmospheric Climate Model (RACMO/ANT) (van Lipzig et al., 2002) for annual surface temperature in $\mathrm{K}(\mathbf{a})$, annual surface pressure in $\mathrm{hPa}(\mathbf{b})$, accumulation rate in m.w.eq.a ${ }^{-1}$ (measured by Vaughan et al., 1999) (c), and wind

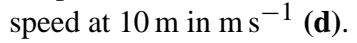

Here, $\gamma_{a}$ and $\gamma_{b}$ are constants derived by tuning the diffusion model with a measured $\mathrm{CO}_{2}$ profile. If the $\mathrm{CO}_{2}$ profile is not available for a location, we need a parameterisation for the tortuosity constants $\left(\gamma_{a}\right.$ and $\left.\gamma_{b}\right)$. This parameterisation is described in Sect. 2.2.
The effective age at PCOD can be derived from a modelled $\mathrm{CO}_{2}$ profile. We used the concentration history of atmospheric $\mathrm{CO}_{2}$ as upper boundary condition in the diffusion model: for 1750 to 1976 derived by Neftel et al. (1985) from the Siple Dome ice core and for 1976 to present from directly measured NOAA-CMDL South Pole data. We constructed a $\mathrm{CO}_{2}$ concentration profile in the firn layer for 150 layers in 
Table 1. Locations and elevations of ten firn core sites used for the parameterisations. The observed meteorological conditions are included; $T$ is the annual surface temperature $(T 10 \mathrm{~m}), A$ the accumulation rate obtained from the referenced studies, $P$ the annual surface pressure and $W$ the wind speed at $10 \mathrm{~m}$ derived from RACMO (except the $P$ and $W$ values for Tunu, these values were obtained from automatic weather stations).

\begin{tabular}{|c|c|c|c|c|c|c|c|c|c|}
\hline Site & Location & $\begin{array}{l}\text { Elevation } \\
\text { (m) }\end{array}$ & $\begin{array}{c}T(\mathrm{~K}) \\
10 \mathrm{~m}\end{array}$ & $\begin{array}{c}A \\
\text { (m.w.eq.a } \\
-1 \text { ) }\end{array}$ & $\begin{array}{c}P \\
\text { (hpa) }\end{array}$ & $\begin{array}{c}W 10 \mathrm{~m} \mathrm{PCOD} \\
\left(\mathrm{m} \mathrm{s}^{-1}\right)\end{array}$ & $\begin{array}{l}\text { Age } \mathrm{CO}_{2} \\
\mathrm{~m}\end{array}$ & $\begin{array}{l}\text { Ref. } \\
\text { years }\end{array}$ & \\
\hline M & $75^{\circ} \mathrm{S}, 15^{\circ} \mathrm{E}$ & 3453 & 221.7 & 0.05 & 615 & 5.7 & 101.7 & 43 & Broeke et al. (2004) \\
\hline S20 & $70^{\circ} 15^{\prime} \mathrm{S}, 4^{\circ} 49^{\prime \prime} \mathrm{E}$ & 48 & 255.5 & 0.28 & 993 & 7.4 & 52.7 & 21 & Broeke et al. (2004) \\
\hline DML & $77^{\circ} \mathrm{S}, 10^{\circ} \mathrm{W}$ & 2300 & 238 & 0.10 & 730 & 6.4 & 74 & 32 & Sturges et al. (2001) \\
\hline Dome C & $75^{\circ} \mathrm{S}, 123^{\circ} \mathrm{E}$ & 3240 & 220.2 & 0.03 & 655 & 5.0 & 98.6 & 40 & Sturges et al. (2001) \\
\hline DEO8-2 & $66^{\circ} 43^{\prime} \mathrm{S}, 113^{\circ} 12^{\prime} \mathrm{E}$ & 1250 & 254 & 1.1 & 850 & 7.0 & 85.2 & 36 & Trudinger et al. (1997) \\
\hline DSS & $66^{\circ} 46^{\prime} \mathrm{S}, 112^{\circ} 48^{\prime} \mathrm{E}$ & 1370 & 251 & 0.60 & 825 & 6.9 & 52.2 & 12 & Trudinger et al. (1997) \\
\hline South Pole & $90^{\circ} \mathrm{S}$ & 2841 & 223.8 & 0.073 & 680 & 6.0 & 119 & 93 & Butler et al. (1999) \\
\hline SipleDome & $81^{\circ} 40^{\prime} \mathrm{S}, 148^{\circ} 49^{\prime} \mathrm{W}$ & 600 & 247.8 & 0.138 & 970 & 6.0 & 56.8 & 39 & Butler et al. (1999) \\
\hline Vostok & $78^{\circ} 28^{\prime} \mathrm{S}, 106^{\circ} 48^{\prime} \mathrm{E}$ & 3502 & 217.65 & 0.022 & 632 & 5.0 & 98 & 90 & Bender et al. (1994) \\
\hline $\operatorname{Tunu}^{a}$ & $78^{\circ} 01^{\prime} \mathrm{N}, 33^{\circ} 59^{\prime} \mathrm{E}$ & 2400 & 244.2 & 0.092 & 777 & 6.3 & 64 & 67 & Butler et al. (1999) \\
\hline
\end{tabular}

${ }^{a}$ Located in Greenland.
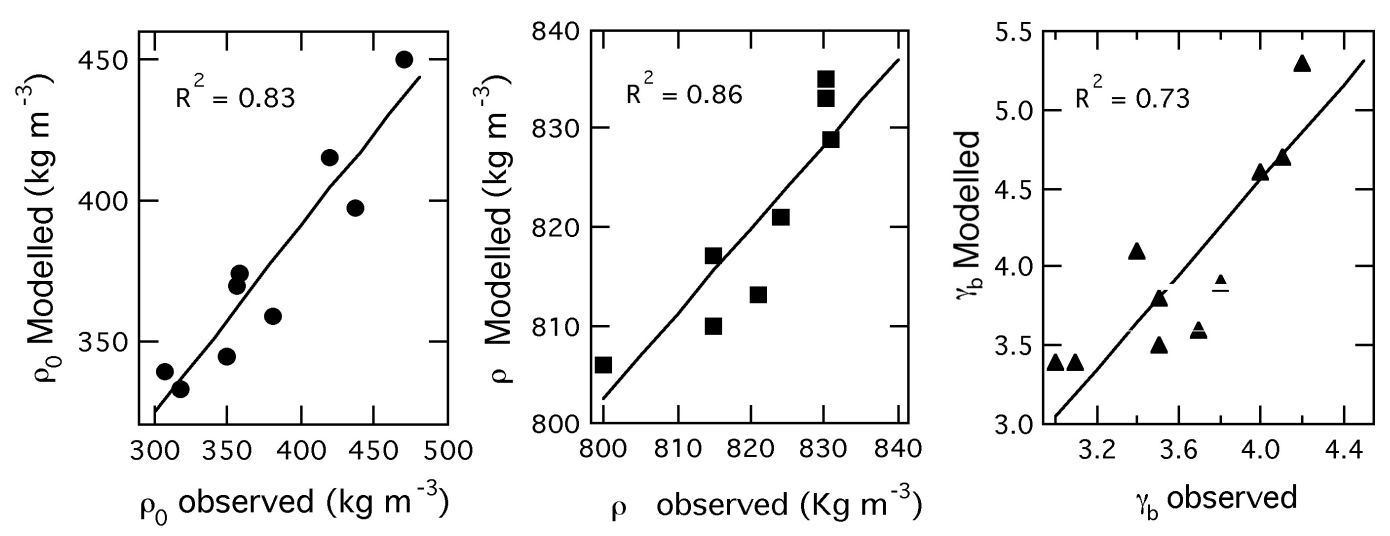

Fig. 3. Parameterisations of $\rho_{0}, \rho_{\mathrm{CO}}$ and $\gamma_{b}$ as a function of the measured and obtained values at the ten specific sites, listed in Table 1 . Note that some values are overlapping

the vertical. Each vertical grid cell contains the same amount of air; therefore, the grid cell size increases near pore closeoff, which is approximately $1 \mathrm{~m}$ for a site were the PCOD is $100 \mathrm{~m}$. The $\mathrm{CO}_{2}$ concentration at PCOD corresponds to the mean age of $\mathrm{CO}_{2}$ at PCOD.

To be independent of the growth rate of atmospheric $\mathrm{CO}_{2}$, we used a block function as atmospheric history at the surface to calculate the mean age of $\mathrm{CO}_{2}$ at PCOD. Because of a smaller concentration gradient in time for the block function then for the atmospheric $\mathrm{CO}_{2}$ history, the mean age is expected to be older than the effective age for $\mathrm{CO}_{2}$. This block function represents 300 model years with the first year having a concentration of one and the following years zero. The mean age and age distribution can be calculated using this block function as described in Schwander et al. (1993) and Trudinger et al. (2002). The age distribution is a measure for the amount of mixing of firn air from different ages, the larger this age spread the more mixing of different aged air occurs. The age distribution is defined as the full width of the age spectrum at half height at PCOD, as defined by Saltzman et al. (2004).

After we parameterised the site-specific density and tortuosity profiles with annual meteorological variables, we used the diffusion model in combination with the Regional Atmospheric Climate Model (RACMO/ANT) and the measured accumulation field of Vaughan et al. (1999) for modelling the age of $\mathrm{CO}_{2}$ at PCOD for entire Antarctica. The RACMO model covers the Antarctic continent with a horizontal grid spacing of $55 \mathrm{~km}$, which is the resolution for the present work as well. RACMO is validated and described in more detail in Van Lipzig et al. (1999 and 2002). Figure 2 shows the meteorological input fields.

Note that the meteorological dataset we have used in this study does not account for mega dunes, melt-layers or 
wind-drifting snow. Melt-layers and mega dunes might have some important effect on the diffusion rate of the firn air in the firn layer. Melt-layers can block the diffusion process, which will result in older firn air at PCOD that estimated in this study. Severinghaus (personal communications) showed that mega dunes will effect the convection of the air in the firn layer near the surface. Due to mega dunes the convection is increased, resulting in faster diffusion rates at the top of the firn layer, this in turn might affect the age of firn air at PCOD being slightly younger than estimated in this study.

\subsection{Parameterisation of the density and tortuosity profiles}

In order to apply the diffusion model over Antarctica, we have to parameterise a number of site-specific parameters and choose a convenient density-depth model to calculate $\rho_{(z)}$. The latter is chosen after comparing six density-depth models with the measured density depth profiles of the ten firn air sites (indicated in Table 1). This comparison in described in more detail in this section with caption "Comparison study of several density-depth models".

To obtain the site-specific parameters $\rho_{\mathrm{CO}}$ and $\gamma_{(z)}$, we applied the firn air diffusion model for nine sites in Antarctica and one in Greenland. Table 1 lists the locations and meteorological conditions of these sites. The measured density profiles were used as input for the diffusion model and the site-specific parameters $\rho_{\mathrm{CO}}$ and $\gamma_{(z)}$ were derived after optimising the model for the measured $\mathrm{CO}_{2}$ profile. The sitespecific variables are parameterised as a linear function of the annual temperature, accumulation, surface pressure and wind speed as derived from RACMO and Vaughan et al. (1999) (the small data set of only 9 measurements does not justify a more sophisticated approach) and different variables were tested, using a standard statistical $\mathrm{F}$ test $(95 \%$ confidence limits). We have chosen this statistical approach, as the physical meaning of the pore close-off density and tortuosity is not completely understood and the data set is too small to justify a detailed physical interpretation. We discuss each site-specific parameter $\left(\rho_{0}, \rho_{\mathrm{CO}}\right.$ and $\left.\gamma_{z}\right)$ separately and conclude this section with a comparison of the modelled ages of $\mathrm{CO}_{2}$ at PCOD and firn air age data given in site-specific studies.

\subsubsection{Comparison study of several density-depth models}

In literature a number of density models are described in the past. Most of these density models are based on semi-empirical relations, like Herron and Langway (1980), Barnola et al. (1991)(density model of Pimienta), Kameda et al. (1994), Craven and Allison (1998) and Spencer et al. (2001), whereas the density model of Arnaud et al. (1998) relays on the physical processes of grain-boundary sliding and power-law creep. Because all these density-models use meteorological parameters (temperature, accumulation, surface pressure and wind speed) as input parameters, they can all be used in this study. For this reason we have compared the models of Arnaud, Craven and Allison, Herron and Langway, Kameda, Pimienta and Spencer with ten measured density profiles (nine for Antarctica and one for Greenland, Table 1). We determined the root mean square error over the entire density profile (every $0.1 \mathrm{~m}$ ) between the density profile obtained from the density model and the measured density profile. The models of Arnaud, Pimienta and Herron and Langway deviated less than $2.5 \%$ on average for the ten measured density profiles, being therefore the most accurate density models from this comparison. All three the models yield density profiles very similar to each other. Although, according to Barnola et al. (1991), the model of Herron and Langway over estimates the PCOD by $10 \mathrm{~m}$ at South Pole (using an accumulation rate of $8 \mathrm{~cm}$.w.eq.a ${ }^{-1}$ ). Nevertheless we have decided to use the Pimienta and Herron and Langway model in our diffusion study, because: a.) it has been validated for a wide climatic range from the polar plateau to costal sites which is not the case for the Arnuad model as far as we know. b.) it is easy to implement over the entire continent, whereas the Arnuad model needs some arbitrary site specific tuning for two parameters. The pimienta model was used as control tool to determine the influence on the main results in terms of PCOD and of age of $\mathrm{CO}_{2}$ at PCOD for the choise of the density model.

It might be noted that the choice of a density-depth model will probably have a smaller effect on the accuracy of the combined diffusion-climate model to determine the age of $\mathrm{CO}_{2}$ at PCOD, compared to the other uncertainties involved, particularly, the tortuosity profile and the accuracy of the meteorological input parameters obtained by the RACMO model.

\subsubsection{Surface snow density}

The surface snow density $\left(\rho_{0}\right)$ is the upper boundary condition in the Herron and Langway density-depth model, which makes $\rho_{0}$ an important parameter. We have used 40 individual measurements (Appendix A) to parameterise $\rho_{0}$ to annual meteorological variables. The parameterisation is given in Eq. (5).

$\rho_{0}=\alpha_{1}+\beta_{1} T+\delta_{1} A+\varepsilon_{1} W$.

The constants $\alpha_{1}, \beta_{1}, \delta_{1}$ and $\varepsilon_{1}$ are given in Table 2. $T$ is the annual average surface temperature in $\mathrm{K}$ (contributing $\sim 70 \%), A$ the accumulation rate in m.w.eq. $\mathrm{a}^{-1}(\sim 2.5 \%)$ and $W$ the annual wind speed in $\mathrm{m} \mathrm{s}^{-1}$ at $10 \mathrm{~m}$ above the surface $(\sim 7.5 \%)$. Figure 3 displays the correlation between the observed surface snow density for the ten sites (Table 1) and the $\rho_{0}$ values calculated with Eq. (5). The derived correlation coefficient between measured and parameterised values is $\mathrm{r}^{2}=0.83$ (99.9\% confidence level). 
Table 2. Parameterisation constants from Eqs. (5), (6) and (7) to couple $\rho_{\mathrm{O}}, \rho_{\mathrm{CO}}$ and $\gamma_{B}$ to meteorological variables.

\begin{tabular}{ccccccc}
\hline & $\alpha$ & $\beta$ & $\delta$ & $\varepsilon$ & $\varphi$ & $1 \sigma$ \\
\hline$\rho_{\mathrm{O}}$ & $7.36 \cdot 10^{-2}$ & $1.06 \cdot 10^{-3}$ & $6.69 \cdot 10^{-2}$ & $4.77 \cdot 10^{-3}$ & & 0.023 \\
$\rho_{\mathrm{CO}}$ & 1.04 & $-1.0 \cdot 10^{-3}$ & $2.66 \cdot 10^{-2}$ & & & 0.006 \\
$\gamma_{b}$ & 1.72 & $-8.4 \cdot 10^{-5}$ & 1.124 & & $2.65 \cdot 10^{-3}$ & 0.27 \\
\hline
\end{tabular}

\subsubsection{Pore close-off density}

The pore close-off density ( $\left.\rho_{\mathrm{CO}}\right)$ is used in the diffusion model as a marker for the location of PCOD. We have obtained the pore close-off density from ten sites (Table 1) to parameterise this parameter to annual meteorological variables and we used the parameterisation of Martinerie et al. (1994) for comparison (Sects. 3.1 and 3.2.). The parameterisation of Martinerie et al. (1994) is only a function of temperature and in shown in Eq. (6a). According to Martinerie et al. (1994), the pore close-off density has typically a value between 800 and $830 \mathrm{~kg} \mathrm{~m}^{-3}$, being strongly site dependent. The result of the parameterisation of ten sites is given in Eq. (6b).

$\rho_{\mathrm{CO}}=\frac{\rho_{\text {ice }}}{\rho_{\text {ice }} V_{c}+1}$ with $V_{c}=6.9510^{-4} T-0.043$

$\rho_{\mathrm{Co}}=\alpha_{2}+\beta_{2} T+\delta_{2} A$.

$V_{c}$ in Eq. (6a) represents the volume of air at pore close-off.

In Eq. (6b), constants $\alpha_{2}, \beta_{2}$ and $\delta_{2}$ are listed in Table 2. Temperature contributes approximately $30 \%$ and accumulation $3 \%$ to $\rho_{\mathrm{CO}}$ in equation $6 \mathrm{~b}$, therefore $\alpha_{2}$ contributes $67(\%)$ to the explained variance. We obtained a negative value for $\beta_{2}$ and a positive value for $\delta_{2}$, which means high values for $\rho_{\mathrm{CO}}$ at locations with low temperatures and high accumulation rates (high values are found for, for example, the Antarctic Plateau). The correlation coefficient between the observed $\rho_{\mathrm{CO}}$ and the $\rho_{\mathrm{CO}}$ calculated with Eq. (6) is $\mathrm{r}^{2}=0.86$ (99.9\% confidence level), as shown in Fig. 3 .

\subsubsection{Tortuosity}

Fabre et al. (2000) studied the measured tortuosity profile for 5 small individual samples taken from four sites on Antractica. From these measurements, they found a linear relationship between the open porosity and the tortuosity. Because this linear relationship is very sensitive to the porosity changes at the surface, which are unknown, Fabre et al. (2002) concluded that this reationship can not be implied on real firn. In this study the tortuosity for the ten sites was derived by tuning each site using the measured $\mathrm{CO}_{2}$ profile and relies therfore on equation 4 . Values between 0.92 and 0.98 were found for the tortuosity constant $\gamma_{a}$, after tuning the diffusion model for each site. This parameter does not show any significant correlation with any meteorological variable. Because $\gamma_{a}$ does not strongly vary among the sites, we decided to use a constant value of $0.95 \pm 0.03$. Values for $\gamma_{b}$ were obtained after tuning the nine sites listed in Table 1, again assuming $\gamma_{a}$ constant and equal to 0.95. Equation (7) describes the parameterisation for $\gamma_{b}$ :

$\gamma_{b}=\alpha_{3}+\beta_{3} T+\delta_{3} A+\varphi_{3} P$

The constants $\alpha_{3}, \beta_{3}, \delta_{3}$ and $\varphi_{3}$ are listed in Table 2. Here, $\gamma_{b}$ is described as a function of annual surface temperature (contributing $\sim 5 \%$ ), accumulation rate $(\sim 1.5 \%)$ and annual surface pressure $(\sim 60 \%)$. The combination of annual surface temperature and accumulation rate in Eq. (7) and the signs of the parameterisation constants ( $\beta$ and $\delta$ ) for these two variables suggest a strong dependence on density. The pressure dependence in Eq. (7) can be understood because the tortuosity is the main tuning parameter in the diffusion model, in which atmospheric pressure is an important parameter. The tortuosity is a function of porosity, capillary radius and capillary pressure (Cunningham and Williams, 1980), which also accounts for the pressure dependence in Eq. (7). Figure 3 presents the accuracy of the parameterisation of $\gamma_{b}$. The correlation coefficient for the modelled $\gamma_{b}$ and the parameterised $\gamma_{b}$ (Eq. 7) is $r^{2}=0.73$ (99.9\% confidence level).

To determine the accuracy of the diffusion model with all three parameterisations included, we compared the modelled $\mathrm{CO}_{2}$ age at PCOD with the firn air age described in sitespecific studies (Butler et al., 1999; Sturges et al., 2001; Trudinger et al., 1997, 2002; Bender et al., 1994, Kaspers et al., 2004). In this modelling experiment we have used the measured meteorological conditions for all ten sites and used the parameterisations to account for the site-specific parameters. Figure 4 shows the comparison. We included the obtained uncertainty $(2 \sigma)$ for the modelled age in this graph (described in detail in Sect. 3.3). The correlation coefficient $\left(\mathrm{r}^{2}\right)$ for modelled $\mathrm{CO}_{2}$ age in firn air at PCOD and the age determined with site-specific parameters is 0.90 . This high correlation and slope close to 1 , suggests that our derived parameterisations used in the firn air diffusion model yield good results and justify the extrapolation over entire Antarctica. 


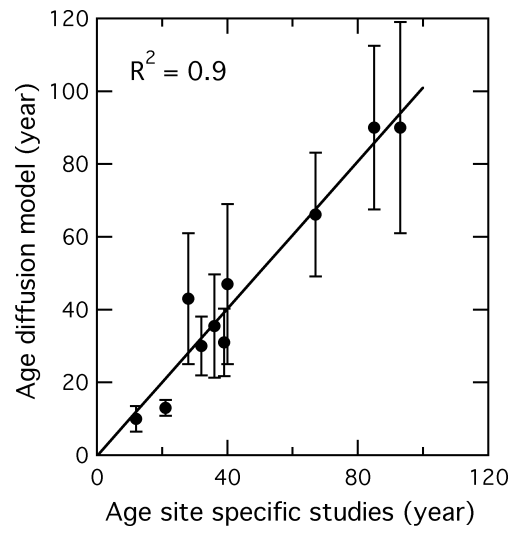

Fig. 4. Comparison between the modelled age of $\mathrm{CO}_{2}$ at $\mathrm{PCOD}$, using the parameterisations for $\rho_{0}, \rho_{\mathrm{CO}}$ and $\gamma_{b}$ (including the model uncertainty, $2 \sigma$ ), and the obtained age of $\mathrm{CO}_{2}$ at PCOD derived from site-specific studies (listed in Table 1).

\section{Results}

\subsection{Results for density}

Figure 5 displays the modelled surface snow density field. High surface snow density is found near the coast in East Antarctica and on the Antarctic Peninsula. The high values are due to the effect of temperature and accumulation and, to a lesser extent, to that of wind speed. On the Antarctic plateau, the surface snow density is on average between $320-360 \mathrm{~kg} \mathrm{~m}^{-3}$, mainly as a result of the low surface temperatures (the structure of Fig. 2a is clearly visible in Fig. 5). The blue ice areas are visible with high surface densities, for example near the Amery ice shelf. The high values on these blue ice areas are a result on the model set-up, when the accumulation rate was zero or even negative the surface density was set to the density of ice.

To model the density profile over the entire Antarctic continent we have used the snow surface density field as input parameter in the density depth model of Herron and Langway (1980) and Pimienta. In Fig. 6a we present the PCOD over Antarctica derived from the Herron and Langway model, using the parameterisations for the surface snow density and the pore-close off density (Eq. 6b). In Fig. 6b the difference is presented between Herron and Langway and Pimienta in PCOD. In this figure the results from Pimientas model are subtracted from the Herron and Langway results (Fig. 6a. Apparently the density model of Pimienta estimates typically 2-14 $\mathrm{m}$ less deep PCODs on the Antarctic plateau and 6$14 \mathrm{~m}$ deeper PCOD near the coastal areas and ice shelves. It should be noted however, that the difference between the density models is smaller than the derived uncertainty when a $(2 \sigma)(5 \%)$ deviation of the density profile is taken into account.

The deepest PCOD's are found by both models, high on the Antarctic plateau between Dome Fuji and Vostok, mostly due to the low temperatures, whereas low values for PCOD

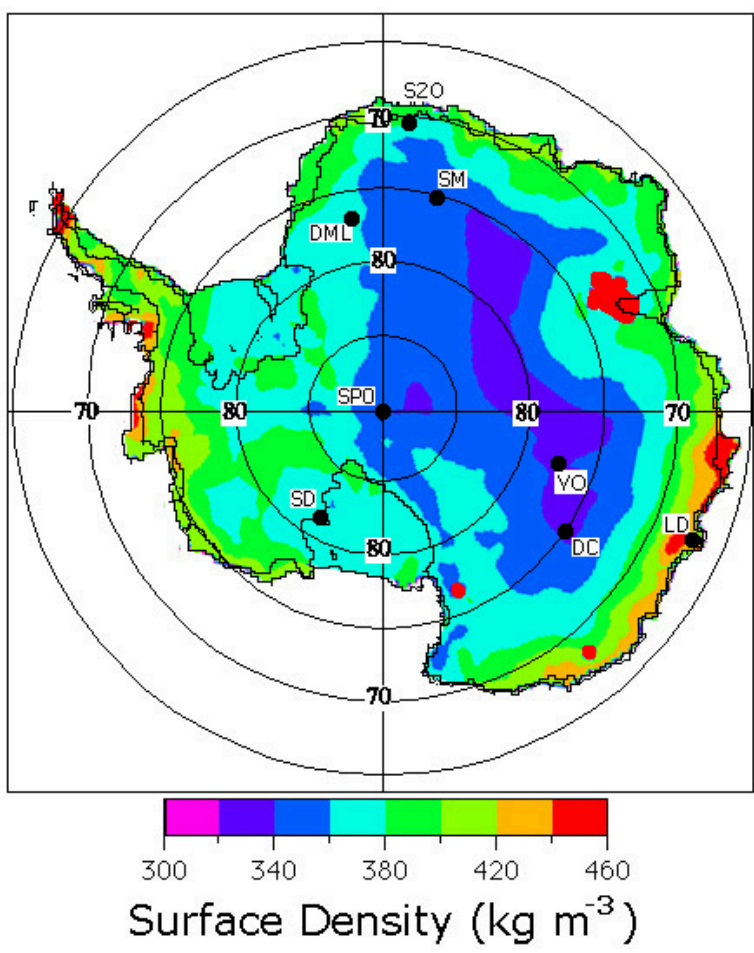

Fig. 5. The surface snow density field in $\mathrm{kg} \mathrm{m}^{-3}$, calculated using Eq. (5) in combination with Table 2.

are found on West Antarctica and the coastal sites. Again the blue ice area at Amery ice shelf is clearly visible, with PCOD values of zero.

Although both the Herron and Langway model and the model of Pimienta presents similar patterns and the location for the deepest PCOD is in both models the same, the PCOD for the location is slightly different being $150 \mathrm{~m}$ and $138 \mathrm{~m}$ for Herron and Langway and Pimienta respectively.

To understand the relation between temperature, accumulation and PCOD presented in Fig. 6, we derived a contour graph (Fig. 7) from a theoretically study with the Herron and Langway model. The dots in Fig. 7 represent the ten firn sites used in this study. Here, the accumulation ranges from 0 to 1.2 m.w.eq. $\mathrm{a}^{-1}$ and temperature from 210 to $260 \mathrm{~K}$. The figure indicates that the rather uncommon combination of low temperature and high accumulation will generally result in a deeper PCOD, which is consisted with other density depth models (Arnaud et al., 1998; Barnola et al., 1991; Kameda et al., 1994; Craven and Allison, 1998; and Spencer et al., 2001). This uncommon combination can explain the relatively deep PCOD at the South Pole $(119 \mathrm{~m})$ compared to Site $\mathrm{M}$ and Dome C $(98.6 \mathrm{~m})$. The two latter sites have a lower annual mean surface temperature, but because South Pole has a higher accumulation rate, the PCOD at South Pole is deeper then the PCOD at Site M and Dome C. However, the deepest pore close-off $(150 \mathrm{~m})$ was found for $72^{\circ} \mathrm{E}, 82^{\circ} \mathrm{S}$ near Dome Argus, where temperature and accumulation are both low. 

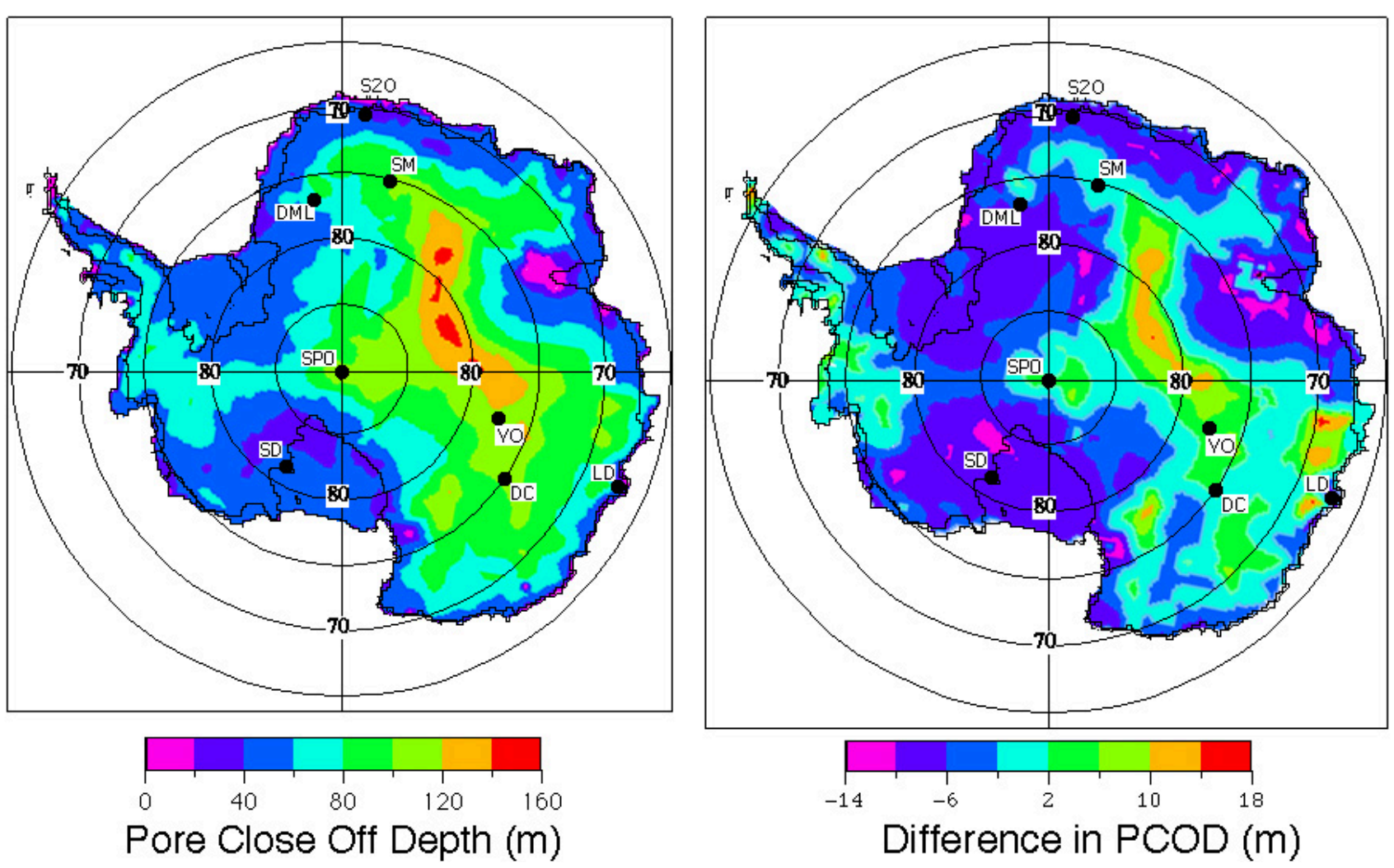

Fig. 6. (A)Depth of the PCOD in m, calculated with the density-depth model of Herron and Langway (1980). The location with the deepest PCOD, being $150 \pm 15 \mathrm{~m}(2 \sigma)$, is found for $72^{\circ} \mathrm{E}$ and $82^{\circ} \mathrm{S}$. (B) Difference in PCOD in m between the PCOD calculated by Herron and Langway (1980) model and the Pimienta (Barnola et al., 1992) model. The difference is presented as Herron and Langway minus Pimienta.

To determine the influence of the pore close-off density parameterisation, we included the pore close-off density parameterisation of Martinerie et al. (1994) (Eq. 6a) in this study. In Fig. 8, we present the difference in derived PCOD when both pore close-off density parameterisations were used. For the deepest PCODs found on the Antarctic plateau this results in a increased PCOD of 3 to $4 \mathrm{~m}$ when the parameterisation obtained in this study is used compared to the parameterisation of Martinerie et al. (1994). For most parts of Antarctica a decrease of the PCOD is found relative to our parameterisation, with the exception of places where the accumulation rate is very high (Peninsula and Law Dome). The parameterisation of Martinerie et al. (1994) only depends on the surface temperature, whereas the parameterisation obtained in this study includes the accumulation rate as well. For this reason we prefer our parameterisation for the pore close-off density in the diffusion model.

\subsection{Age of $\mathrm{CO}_{2}$ at PCOD}

For each grid point, the diffusion model yields the $\mathrm{CO}_{2}$ concentration at PCOD. From the known history of $\mathrm{CO}_{2}$, the $\mathrm{CO}_{2}$ effective age of the air at PCOD can be readily deter- mined (Schwander et al., 1993). Figure 9a shows the results. The model uning Herron and Langway density model predicts that the oldest $\mathrm{CO}_{2}$ in firn air is located in an area between Dome Fuji, Dome Argos and Vostok. This area is characterized by a large PCOD, low temperatures and relatively high atmospheric pressure and accumulation compared to the domes. This can be understood as follows. At the lowtemperature locations, the PCOD is deep. The age of $\mathrm{CO}_{2}$ at PCOD is furthermore depended by the diffusion rate. Here temperature had a direct effect on the diffusion rate; at low temperatures the diffusion rate is low, yielding older air at PCOD. For low surface pressure the effect on the diffusion rate is opposite to that of temperature.Because molecules collide less to each other at lower pressures, the diffusion rateb will be faster at lower pressures. The result of Fig. 9a is consisted with the conclusions of Fabre et al. (2000), where they studied the tortuosity and diffusion rate for 4 sites on Antarctica. The model predicts the oldest effective $\mathrm{CO}_{2}$ age in firn air at PCOD to be 125 years and that it can be found at $43^{\circ} \mathrm{E}$, $78^{\circ} \mathrm{S}$.

In Fig. $9 b$ the effect of the choice for the density model is presented. Here the difference in effective age for $\mathrm{CO}_{2}$ calculated with the Herron and Langway model minus the 


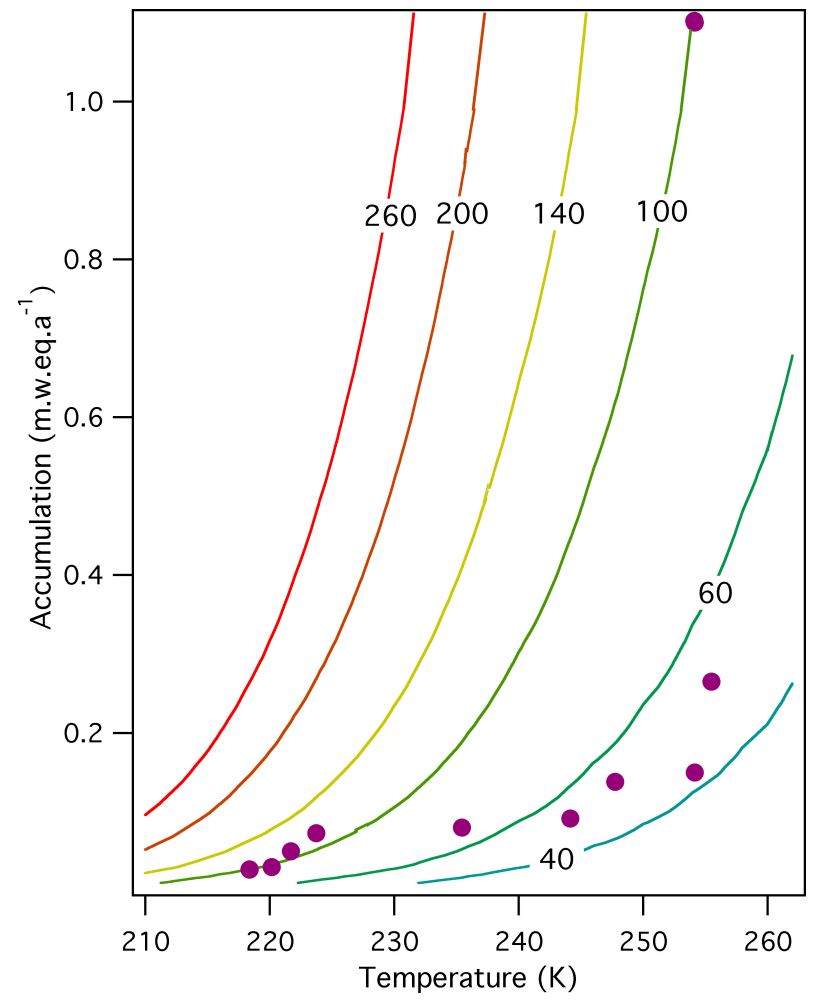

Fig. 7. Theoretically determined PCOD, using the density-depth model Herron and Langway (1980). The contour plot represents different PCOD's in $\mathrm{m}$ with varying annual surface temperatures and accumulation rates, varying from, respectively, 210 to $260 \mathrm{~K}$ and 0.01 to 1.2 m.w.eq. $\mathrm{a}^{-1}$. The dots represent the PCOD's of ten sites (Table 1), these show the same pattern as the theoretically derived lines.

effective age for $\mathrm{CO}_{2}$ calculated with the Pimienta model is presented. Due to the less deep PCODs calculated by the Pimienta model, the effective age for $\mathrm{CO}_{2}$ is approximately 10 years younger than when calculated with the Herron and Langway model for the Antarctica Plateau. Like the choice of the density model also the pore close off density parameterisation influences the calculated age of firn air at PCOD and the location of where the oldest air can be found. To investigate the influence of the pore close-off density parameterisation on the effective age of $\mathrm{CO}_{2}$ at PCOD, the parameterisation of Martinerie et al. (1994) is used. The effective ages of $\mathrm{CO}_{2}$ at PCOD are within the same order of magnitude and deviate approximately $2-5$ years with respect to the results using Eq. (6b); And 2. the location of the oldest firn air can be found in the area between Dome Fuji, Dome Argos and Vostok, consistent with Fig. 9a.

To be independent of the strong growth rate of atmospheric $\mathrm{CO}_{2}$ in the recent history, we have used a block function to simulate the atmospheric history at the surface to calculate the mean age of $\mathrm{CO}_{2}$ as presented in Fig. 10a. The procedure is also adopted by Schwander et al. (1993) and Trudinger et al. (2002). The results of Fig. 10a are derived from the diffu-

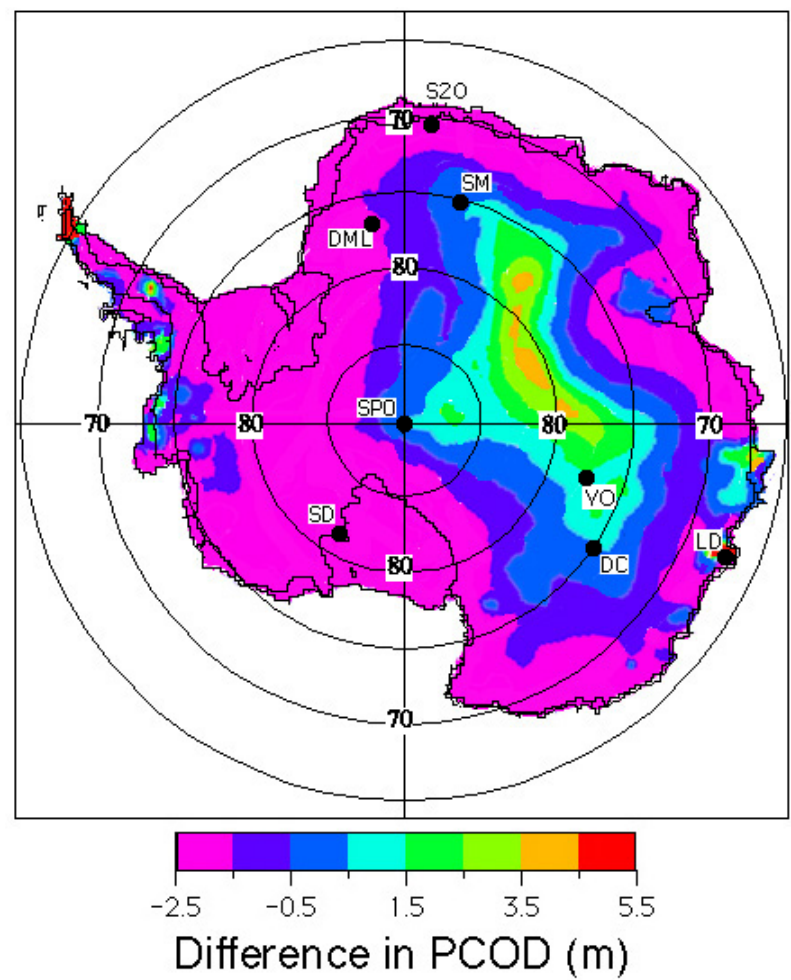

Fig. 8. The difference in PCOD obtained from calculating the PCOD using the pore close-off density parameterisation of Eq. (6b), minus the PCOD calculated using the parameterisation of Martinerie et al. (1994) (Eq. 6a). The difference in PCOD is presented in metres.

sion model with the density model of Herron and Langway is incorporated. The use of the block function yielded an age spectrum of different aged air at PCOD, which enabled the age distribution to be calculated over the Antarctic continent as presented in Fig. 10b. Because the diffusion rate of firn air is dependent on the concentration gradient in time at the surface, the mean age presented in Fig. 10a is older than the effective age of $\mathrm{CO}_{2}$ presented in Fig. 9a and the exact location where the oldest firn air can be found is also different. Overall, like Fig. 9a, the oldest firn air can be found at the Antarctica plateau, on a location with very cold annual temperatures, relatively high accumulation rates and relatively high surface pressures. Similar to the mean age, the largest age distributions are found on the Antarctic plateau (Fig. 10a). The firn air with the oldest mean age is expected be 156 years and can be found at $83^{\circ} \mathrm{S}$, with an expected age distribution of 103 years. The youngest firn air at PCOD can be found at the coast and at the coastal side of the mountain ranges (specifically near the Trans Antarctic Mountains). The low age of $\mathrm{CO}_{2}$ at PCOD near the mountains is mostly due to relatively high temperatures found at these locations. The oldest air outside the East Antarctic plateau at PCOD is found on Berkner Island. 

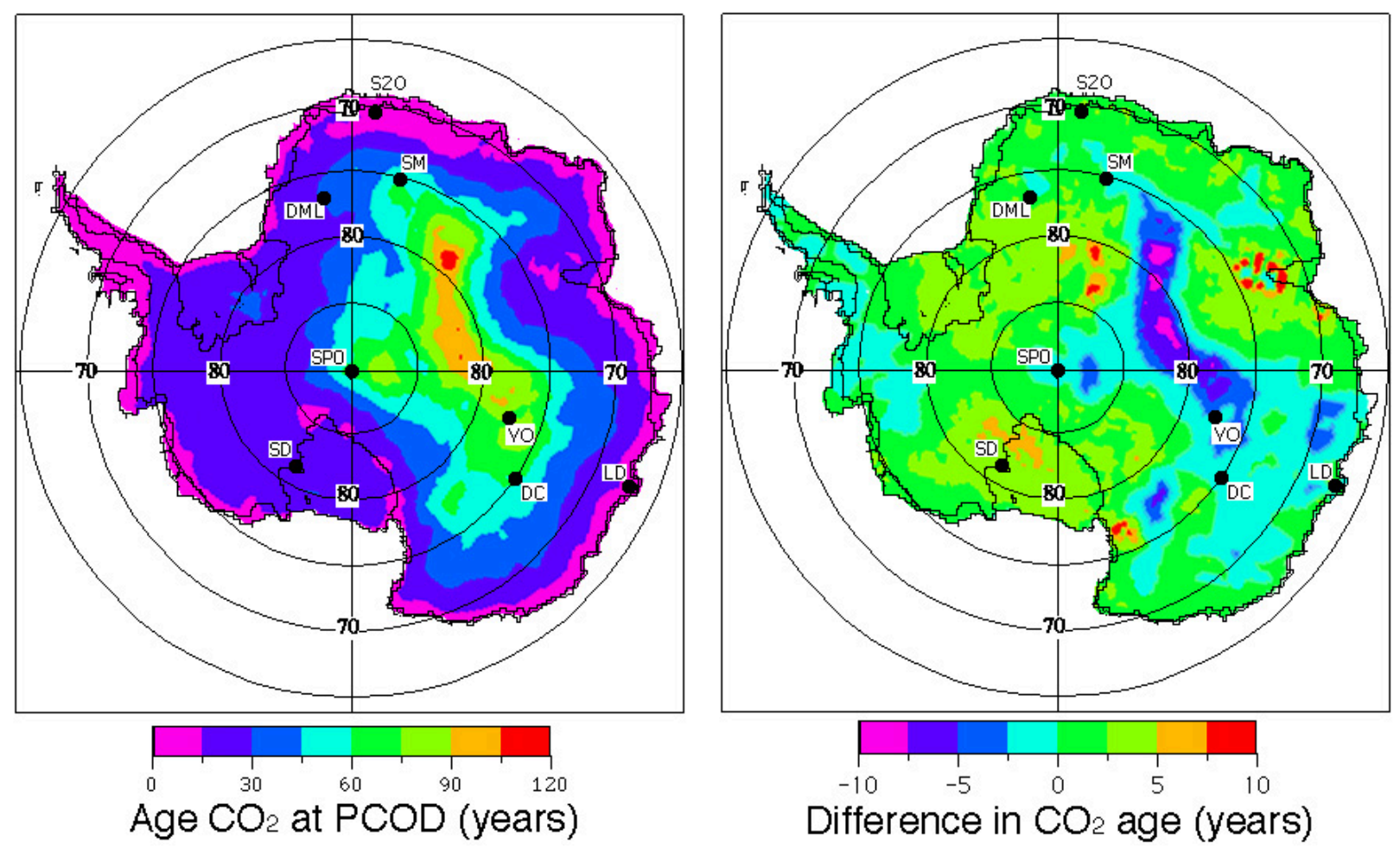

Fig. 9. (A)The effective $\mathrm{CO}_{2}$ age at PCOD in years for the entire Antarctic continent using the Herron and Langway density model. The oldest $\mathrm{CO}_{2}$ at $\mathrm{PCOD}$, being $125 \pm 19$ years $(1 \sigma)$, is predicted as located at $43^{\circ} \mathrm{E}$ and $78^{\circ} \mathrm{S}$. $(\mathrm{B})$ repreents the difference in $\mathrm{CO}_{2}$ effective age when the Herron and Langway or the Pimienta model is used. Here the effective age using the Pimienta density model is subtracted from the results using the Herron and Langway density model.

As an example for trace gas records, we predict a mean age of 187 years at PCOD for methyl chloride at $82^{\circ} \mathrm{E}, 83^{\circ} \mathrm{S}$. The difference in mean age between methyl chloride and $\mathrm{CO}_{2}$ is due to the different molecular mass and gas specific diffusion coefficient $\left(D_{12}\right)$ of methyl chloride versus $\mathrm{CO}_{2}$ (Kaspers et al., 2004). Sampling firn air at $82^{\circ} \mathrm{E}, 83^{\circ} \mathrm{S}$, will therefore significantly lengthen the present longest firn air record from South Pole, being 80 years (Butler et al., 1999). Such data could be compared with measurements of methyl chloride concentrations in Siple Dome ice presented by Aydin et al. (2004), showing a sinusoidal ( $\sim 100$ year period) atmospheric concentration over the past 300 years.

\subsection{Deriving the model uncertainty}

We performed a number of sensitivity tests to estimate the uncertainty in the modelled PCOD and firn air age. We tested the effect of errors in the parameterisations of $\rho_{\mathrm{CO}}, \gamma_{b}$ and the parameterised density profile. $\rho_{\mathrm{CO}}$ and $\gamma_{b}$ are important for the location of the PCOD and the open pore structure of the firn layer, while errors in the density profile will introduce an error in diffusion over the total firn air column.

We varied $\rho_{\mathrm{CO}}$ by $12 \mathrm{~kg} \mathrm{~m}^{-3}$ (twice the uncertainty of the parameterisation). This typically introduced a change of $5 \mathrm{~m}$ in the PCOD at the 'deep' locations (PCOD deeper than $100 \mathrm{~m}$ ) and 1 to $2 \mathrm{~m}$ deviation at the more 'shallow' locations (around $60 \mathrm{~m}$ ). This change produced a change of approximately $12 \%$ in the mean age of $\mathrm{CO}_{2}$ at PCOD. Varying the tortuosity profile $\left(\gamma_{b}\right)$ with twice the uncertainty (15\%) yielded a deviation of $30 \%$ for the mean age of $\mathrm{CO}_{2}$ at PCOD. So the results appear to be more sensitive to the uncertainty in $\gamma_{b}$ than in $\rho_{\text {CO }}$.

We systematically varied $\rho_{(z)}$ with $5 \%$ along the entire profile, at $0.1 \mathrm{~m}$ resolution, which is twice the uncertainty of the Herron and Langway model. This had a significant effect on the PCOD and the age of $\mathrm{CO}_{2}$ at PCOD. Figure 11 shows the derived uncertainty $(2 \sigma)$ for the PCOD. The effect is most pronounced for the East Antarctic Plateau. For the deepest pore close-off location $(150 \mathrm{~m})$ at $72^{\circ} \mathrm{E}, 82^{\circ} \mathrm{S}$, a $15 \mathrm{~m}$ uncertainty is found, being $10 \%(2 \sigma)$. The deviation of the density profile yielded typically an uncertainty $(2 \sigma)$ of 15-20\% over Antarctica (Fig. 11) for determining the PCOD. This yields an uncertainty of approximately $30 \%$ in the mean age of $\mathrm{CO}_{2}$ at PCOD.

To determine the uncertainty $(2 \sigma)$ in the mean $\mathrm{CO}_{2}$ age at pore close-off, all three uncertainties (twice the values given in Table 2 for $\rho_{\mathrm{CO}}$ and $\gamma_{b}$, and $5 \%$ for the Herron and Langway density model) were imposed. Figure 12 displays 

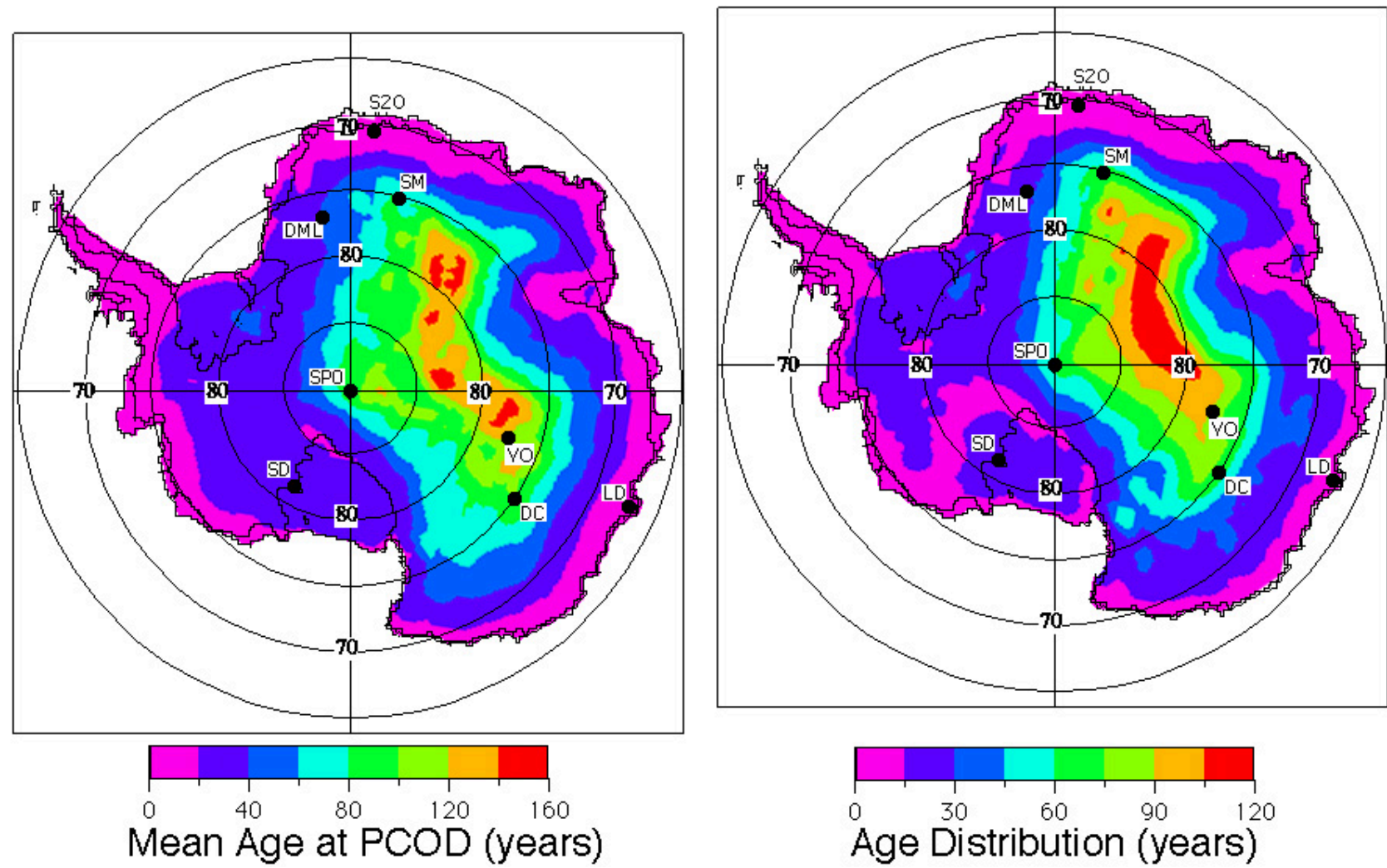

Fig. 10. (A)The mean $\mathrm{CO}_{2}$ age at PCOD in years, calculated using a block function for the atmospheric history as presented in Trudinger et al., 2002. The mean age is calculated to be $156 \pm 24$ years at $82^{\circ} \mathrm{E}, 83^{\circ} \mathrm{S}$ (B) The age distribution at PCOD, defined as the full width at half height (Saltzman et al., 2003) for the mixing of ages at PCOD. For the location $82^{\circ} \mathrm{E}, 83^{\circ} \mathrm{S}$ the age distribution is calculated to be 103 years.

Table 3. Parameterisation constants from Eqs. (7), (8) and (10) relating the final model results directly to meteorological variables.

\begin{tabular}{lccccc}
\hline & $\alpha$ & $\beta$ & $\delta$ & $\varphi$ & $1 \sigma$ \\
\hline$h_{\mathrm{PCO}}$ & 500 & -1.8 & 0.34 & & 10 \\
MeanAge $_{\mathrm{CO}_{2}, \text { PCOD }}$ & 445 & -1.98 & 0.065 & 0.090 & 21 \\
AgeDistribution $_{\mathrm{CO}_{2}, \text { PCOD }}$ & 629 & -2.74 & & 0.080 & 13
\end{tabular}

the result. The largest absolute deviations are found for the plateau. At $82^{\circ} \mathrm{E}, 83^{\circ} \mathrm{S}$, the location of the oldest firn air, the uncertainties are 22 years $(1 \sigma)$ and 35 years $(2 \sigma)$ for 156 year-old air. Overall, the mean age of $\mathrm{CO}_{2}$ at PCOD has an average uncertainty of $35 \%(2 \sigma)$ for locations with younger

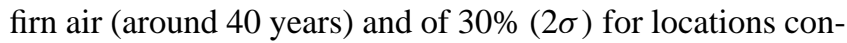
taining old firn air (100 years and older).

\subsection{Parameterisations of the results}

From the obtained results (Sects. 3.1 to 3.3), a second parameterisation step is proposed. Here, parameterised formu- las have been formulated to calculate the PCOD $\left(h_{\mathrm{PCO}}\right)$, the $\mathrm{CO}_{2}$ mean age at PCOD (mean age $\left.\mathrm{CO}_{2}, \mathrm{PCO}\right)$ and the age distribution of the mean age for $\mathrm{CO}_{2}$ at pore close-off (age distribution $\mathrm{CO}_{2}, \mathrm{PCO}$ ), by using the surface meteorological conditions. The idea of these parameterisations is that they can easily be used in the field to gain knowledge about the expected PCOD and mean age of $\mathrm{CO}_{2}$ at PCOD, when the meteorological conditions are known for a specific site, but without tuning a firn diffusion model.

$h_{\mathrm{PCO}}=\alpha_{1}+\beta_{1} T+\delta_{1} A$

MeanAge $_{\mathrm{CO}_{2}, \mathrm{PCO}}=\alpha_{2}+\beta_{2} T+\delta_{2} A+\varphi_{2} P$

AgeDistribution $_{\mathrm{CO}_{2}, \mathrm{PCO}}=\alpha_{3}+\beta_{3} T+\varphi_{3} P$

In these equations, $T$ is the annual mean temperature in $\mathrm{K}$, $A$ the accumulation rate in m.w.e. $\mathrm{a}^{-1}$ and $P$ the atmospheric pressure in $\mathrm{hPa}$. The meteorological parameters are based on the RACMO data and Vaughan et al. (1999) accumulation adat. The surface atmsopheric pressure can also be easily parameterised in terms of elevation, as described in Van den Broeke et al. (1999). The parameterisation constants are presented in Table 3. 


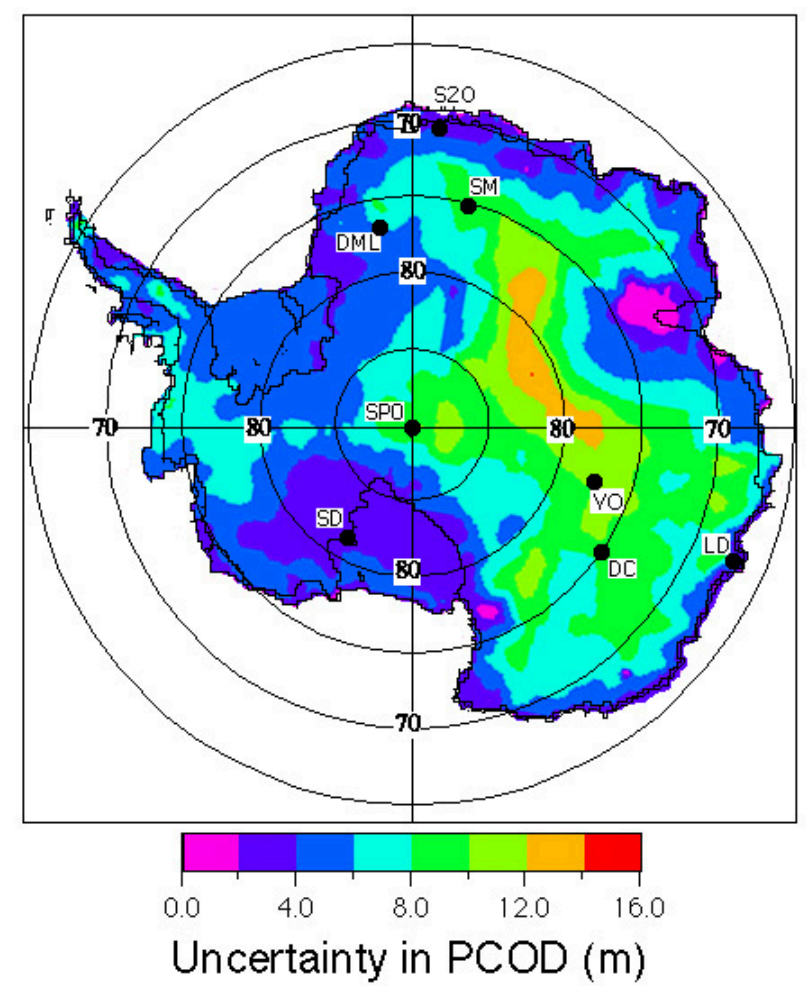

Fig. 11. The uncertainty $(2 \sigma)$ of the PCOD (m), obtained after deviating the density profile $5 \%$ every $0.1 \mathrm{~m}$ by using the Herron and Langway (1980) model.

We have compared the values for PCOD and mean age calculated using the parameterisations of Eqs. (8) and (9) using the observed meteorology of Table 1 with the derived values for PCOD and mean age given in Table 1. This comparison yielded a correlation coefficient $\left(\mathrm{r}^{2}\right)$ of 0.83 (slope is 0.83 ) for comparing the PCOD values of Table 1 with the values obtained from the parameterisation, and a correlation coefficient $\left(\mathrm{r}^{2}\right)$ of 0.55 (slope is 0.52$)$ for the mean age comparison.

\section{Summary and conclusions}

We successfully combined a modelled meteorological dataset based on output from an atmospheric model for the period 1980-1993 (van Lipzig et al., 2002) and a firn air diffusion model. In order to make this combination, we used a density depth model and parameterised the surface density, pore close-off density and the tortuosity of the firn layer. We have used the Herron and Langway density-depth model in the diffusion model after comparing 5 density depth models. We found that the model of Arnaud et al. (1998), Pimienta (Barnola et al., 1992) and Herron and Langway, (1980) pro-

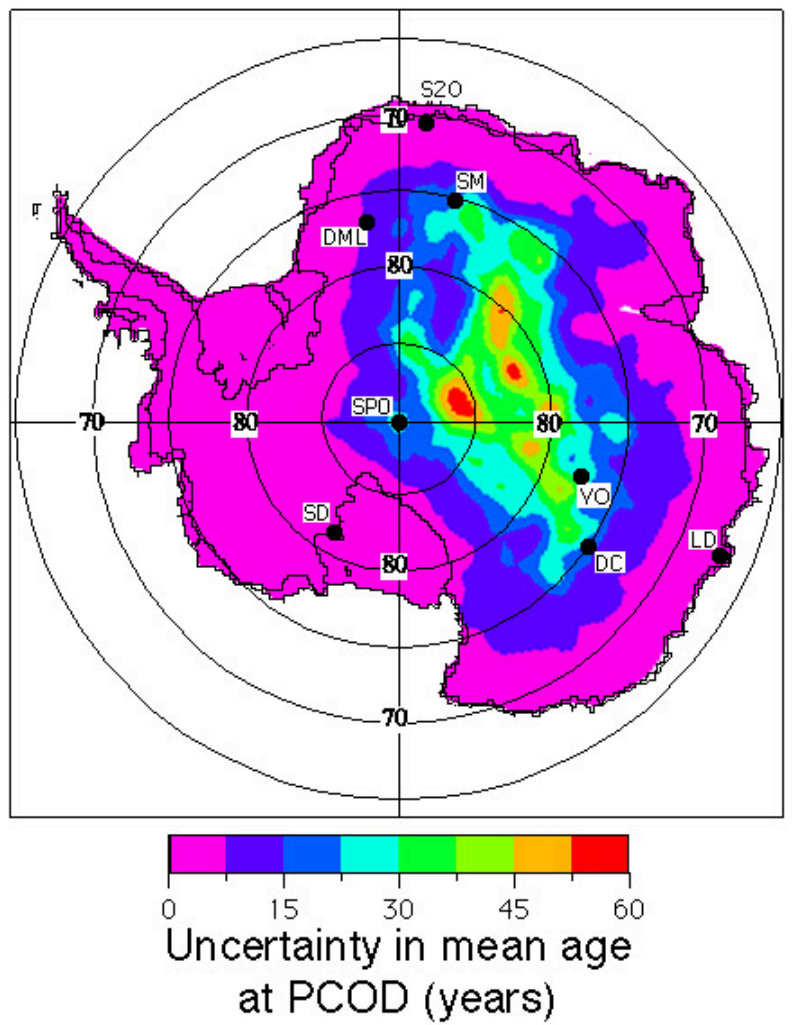

Fig. 12. The model uncertainty in derived mean age for $\mathrm{CO}_{2}$ at $\operatorname{PCOD}(2 \sigma$, in years). Here, twice the uncertainty $(2 \sigma)$ for the tortuosity $\left(\gamma_{b}\right)$ and the pore close-off density $\left(\rho_{\mathrm{CO}}\right)$ and a deviation of $5 \%$ in the modelled density profile were taken into account.

vide the most accurate results, when compared to ten measured density profiles. To derive the parameterisations for $\rho_{0}, \rho_{\mathrm{CO}}$ and $\gamma_{(z)}$, we used ten firn air analyses (Butler et al., 1999; Sturges et al., 2001; Trudinger et al., 1997; Kaspers et al., 2004; Table 1). The results of this parameterisation, demonstrate, that the tortuosity and surface density can be related to meteorological parameters, to our knowledge for the first time. The accuracy of the parameterisations for $\rho_{0}, \rho_{\mathrm{CO}}$ and $\gamma_{(z)}$ was determined by comparing our diffusion model results with earlier published firn air ages at pore close-off (Table 1). A correlation coefficient $\left(\mathrm{r}^{2}\right)$ of 0.9 and a slope close to 1 , was found for $\mathrm{CO}_{2}$ ages at pore close-off derived from our study (with only 4 meteorological variables as input) and the mean $\mathrm{CO}_{2}$ ages from published firn air analyses. This correlation coefficient gives confidence in the accuracy of our approach. With the diffusion model, the parameterisations yielded a surface snow density field for the entire Antarctic continent. For this surface snow density, the annual surface temperature and accumulation rate are the most important parameters, but wind speed also plays an important role, especially for the coastal sites and near mountain ranges. The lowest values for the surface snow density are found for the East Antarctic plateau, where annual surface 
temperature and accumulation rate are low. Incorporation of the surface snow density field in the density-depth model of Herron and Langway (1980) yielded the PCOD. After modelling the PCOD for Antarctica, a maximum PCOD of $150 \pm 15 \mathrm{~m}(2 \sigma)$ was found for $72^{\circ} \mathrm{E}, 82^{\circ} \mathrm{S}$. The pore closeoff density parameterisation is responsible for 3 to $4 \mathrm{~m}$ deviation in PCOD, when comparing the parameterisation for $\mathrm{CO}$ in this study (dependent on temperature and accumulation) and the CO parameterisation of Martinerie et al. (1994) only temperature dependent.

We took the $\mathrm{CO}_{2}$ data for the past 250 years, as upper boundary condition and modelled the diffusion of $\mathrm{CO}_{2}$ into the firn layer until PCOD. This enabled us to determine the effective age of $\mathrm{CO}_{2}$ at PCOD for the entire Antarctic continent. The choice of the density model, Herron and Langway or Pimienta, can account for a difference in effective age at PCOD of 10 years. The oldest effective age for $\mathrm{CO}_{2}$ at PCOD using Herron and Langway is found at $43^{\circ} \mathrm{E}, 78^{\circ} \mathrm{S}$ being 125 years. This study indicates, that the mean and effective age of the $\mathrm{CO}_{2}$ at PCOD is older at sites with low annual temperature and relatively high accumulation and surface pressure although the exacted locations deviate. This result is consistent with the conclusions of Fabre et al. (2000). An important result from the combination between the diffusion model and the RACMO climate model is the prediction of the location where the oldest $\mathrm{CO}_{2}$ in firn air (mean age) can be sampled. This is between Dome Fuji, Dome Argus and Vostok. The oldest air is found at $82^{\circ} \mathrm{E}, 83^{\circ} \mathrm{S}$, using our $\rho_{\text {CO }}$ parameterisation. However, the exact location is debatable, as indicated by the results of the effective age and in case the Martinerie et al. (1994) $\rho_{\mathrm{CO}}$ parameterisation was used. The mean age of the $\mathrm{CO}_{2}$ at PCOD at $82^{\circ} \mathrm{E}, 83^{\circ} \mathrm{S}$ is expected to be $156 \pm 22(1 \sigma)$ and $35(2 \sigma)$ years. Until now, no firn gas analyses have been carried out for that location. To give an example (of the practical usefulness of our results), for firn air trace gas analyses, we predict an mean age of 187 years at PCOD for methyl chloride at $82^{\circ} \mathrm{E}, 83^{\circ} \mathrm{S}$, which would yield a record that is approximately two times longer than the trace gas record of Butler et al., (1999). A number of sensitivity tests were performed to gain insight about model uncertainty. Here, tests were performed where the pore close-off density $\left(\rho_{\mathrm{CO}}\right)$ and tortuosity $\left(\gamma_{(z)}\right)$ parameterisations were varied twice the uncertainty $(2 \sigma)$ in the diffusion model and the density profile was varied $5 \%$ over the total firn column. The sensitivity test revealed that the tortuosity parameterisation and the modelling of density profile caused the largest uncertainty. The derived model uncertainty was $35(\%)(2 \sigma)$ for locations containing younger firn

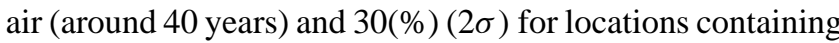
older firn air (older than 100 years). The model uncertainty can be significantly improved with better parameterisations for the tortuosity, pore close-off density and surface snow density, for which more firn air data need to become available first. 
Appendix

Appendix A

\begin{tabular}{|c|c|c|c|c|c|c|c|c|}
\hline Site & Location & & Elevation (m) & T $10 \mathrm{~m}(\mathrm{~K})$ & A (m.w.eq. $\left.{ }^{-1}\right)$ & $\mathrm{WS} \mathrm{m} \mathrm{s}^{-1}$ & $\rho_{0} \mathrm{~kg} \mathrm{~m}^{-3}$ & Ref. \\
\hline $\mathrm{M}$ & 74'59'59"S & 15'00'06"E & 3453 & 221.7 & 0.05 & 5.7 & 0.307 & Kaspers et al., 2004 \\
\hline $\mathrm{S} 20$ & $70^{\prime} 14 ' 30 " \mathrm{~S}$ & $0.4^{\prime} 48^{\prime} 40^{\prime \prime} \mathrm{E}$ & 48 & 255.5 & 0.28 & 7.4 & 0.437 & Kaspers et al., 2004 \\
\hline DML & $77 \mathrm{~S}$ & $10 \mathrm{~W}$ & 2300 & 238 & 0.10 & 6.4 & 0.381 & Sturges et al., 2001 \\
\hline Dome C & $75 \mathrm{~S}$ & $123 \mathrm{E}$ & 3240 & 220.2 & 0.03 & 5.0 & 0.318 & Sturges et al., 2001 \\
\hline South Pole & $90 \mathrm{~S}$ & & 2841 & 223.8 & 0.073 & 6.0 & 0.427 & Butler et al., 1999 \\
\hline Siple Dome & $81^{\prime} 40$ 'S & $148^{\prime} 49^{\prime} \mathrm{W}$ & 600 & 247.8 & 0.138 & 6.0 & 0.358 & Butler et al., 1999 \\
\hline DSS & $66^{\prime} 46^{\prime} \mathrm{S}$ & $112^{\prime} 48^{\prime} \mathrm{E}$ & 1370 & 251 & 0.60 & 6.9 & 0.419 & Trudinger et al., 1997 \\
\hline DEO8-2 & $66 ' 43 ' S$ & $113^{\prime} 12^{\prime} \mathrm{E}$ & 1250 & 254 & 1.10 & 7.0 & 0.470 & Trudinger et al., 1997 \\
\hline Tunu (green) & $78^{\prime} 01{ }^{\prime} \mathrm{N}$ & $33^{\prime} 599^{\prime} \mathrm{E}$ & 2400 & 244.2 & 0.092 & 6.3 & 0.357 & Butler et al., 1999 \\
\hline Vostok & $78^{\prime} 28^{\prime} \mathrm{S}$ & $106^{\prime} 48^{\prime} \mathrm{E}$ & 3502 & 217.65 & 0.022 & 5.0 & 0.300 & Bender et al., 1994 \\
\hline Old Byrd & $79 ' 59$ & $120^{\prime} 01^{\prime} \mathrm{W}$ & 1510 & 245.2 & 0.16 & 7.6 & 0.380 & Gow, 1968 \\
\hline Ro.Is.Dome & $79^{\prime} 22^{\prime}$ & $161^{\prime} 41^{\prime} \mathrm{W}$ & & 250.5 & 0.16 & 6.7 & 0.370 & Herron and Langway., 1980 \\
\hline Little Am V & $78^{\prime} 10^{\prime}$ & $162^{\prime} 13^{\prime} \mathrm{W}$ & 43 & 249.2 & 0.22 & 6.7 & 0.360 & Gow, 1968 \\
\hline $\mathrm{J}-9$ & $82^{\prime} 22^{\prime}$ & $168^{\prime} 40^{\prime} \mathrm{W}$ & & 245.3 & 0.09 & 5.6 & 0.350 & Herron and Langway., 1980 \\
\hline $\mathrm{C}-7-3$ & $78^{\prime} 20^{\prime}$ & $179 ' 51^{\prime} \mathrm{E}$ & & 247.6 & 0.11 & 6.8 & 0.340 & Herron and Langway., 1980 \\
\hline Site A & 71'54'S & $03^{\prime} 05^{\prime} \mathrm{E}$ & 1520 & 247.6 & 0.14 & 4.7 & 0.362 & Van den Broeke et al., 1999 \\
\hline Site B & $72^{\prime} 08^{\prime} 01^{\prime \prime}$ & $03^{\prime} 10^{\prime} 31^{\prime \prime}$ & 2044 & 245.1 & 0.17 & 5.4 & 0.356 & Van den Broeke et al., 1999 \\
\hline Site C & $72^{\prime} 15^{\prime} 04^{\prime \prime}$ & $02^{\prime} 53^{\prime} 28^{\prime \prime}$ & 2400 & 242.9 & 0.12 & 5.4 & 0.343 & Van den Broeke et al., 1999 \\
\hline Site D & $72^{\prime} 30^{\prime}$ & $0^{\prime} 3$ & 2610 & 238.4 & 0.11 & 6.3 & 0.373 & Van den Broeke et al., 1999 \\
\hline Site E & $72^{\prime} 40^{\prime} 42^{\prime \prime}$ & 03'39'46" & 2751 & 236.3 & 0.06 & 4.0 & 0.407 & Van den Broeke et al., 1999 \\
\hline Site F & $72^{\prime} 51^{\prime} 41^{\prime \prime}$ & $04^{\prime} 21^{\prime} 05^{\prime \prime}$ & 2840 & 234.7 & 0.02 & 4.4 & 0.375 & Van den Broeke et al., 1999 \\
\hline Site G & $73^{\prime} 02^{\prime} 26^{\prime \prime}$ & $05^{\prime} 02^{\prime} 39^{\prime \prime}$ & 2929 & 233.1 & 0.03 & 4.4 & 0.355 & Van den Broeke et al., 1999 \\
\hline Site $\mathrm{H}$ & 73'23'11" & $06^{\prime} 27^{\prime} 38^{\prime \prime}$ & 3074 & 230.5 & 0.04 & 5.2 & 0.366 & Van den Broeke et al., 1999 \\
\hline Site I & $73^{\prime} 43^{\prime} 27^{\prime \prime}$ & $07^{\prime} 56^{\prime} 26^{\prime \prime}$ & 3174 & 228.6 & 0.05 & 5.8 & 0.343 & Van den Broeke et al., 1999 \\
\hline Site $\mathrm{J}$ & $74^{\prime} 02^{\prime} 41^{\prime \prime}$ & 09'29'30" & 3268 & 226.9 & 0.06 & 6.5 & 0.338 & Van den Broeke et al., 1999 \\
\hline Site K & $74 ' 211^{\prime} 16^{\prime \prime}$ & $11^{\prime} 06^{\prime} 13^{\prime \prime}$ & 3341 & 225.4 & 0.05 & 6.7 & 0.343 & Van den Broeke et al., 1999 \\
\hline Site L & 74'38'50" & $12^{\prime} 47^{\prime} 27^{\prime \prime}$ & 3406 & 223.9 & 0.05 & 6.5 & 0.341 & Van den Broeke et al., 1999 \\
\hline
\end{tabular}

\begin{tabular}{|c|c|c|c|c|c|c|c|c|}
\hline Site S15 & 71'11'30" & $04^{\prime} 35^{\prime} 50^{\prime \prime}$ & 800 & 252.9 & 0.24 & 3.8 & 0.389 & Van den Broeke et al., 1999 \\
\hline 5 & $87^{\prime} 48^{\prime} 18^{\prime \prime} \mathrm{S}$ & $59^{\prime} 12^{\prime} \mathrm{E}$ & 2989 & 219.7 & 0.06 & 5.88 & 0.396 & Cameron et al., 1968 \\
\hline $5 a$ & idem & idem & 3006 & 219.0 & 0.055 & 5.88 & 0.387 & Cameron et al., 1968 \\
\hline 6 & $87^{\prime} 16^{\prime} 48^{\prime \prime}$ & $58^{\prime} 54^{\prime}$ & 3034 & 221.7 & 0.072 & 6.367 & 0.411 & Cameron et al., 1968 \\
\hline 7 & $86^{\prime} 45^{\prime}$ & $58 ' 36$ & 3106 & 221.6 & 0.048 & 5.84 & 0.374 & Cameron et al., 1968 \\
\hline 9 & $86^{\prime} 44^{\prime} 30^{\prime \prime}$ & $40^{\prime} 00^{\prime}$ & 3022 & 223.6 & 0.060 & 6.986 & 0.393 & Cameron et al., 1968 \\
\hline 10 & $86^{\prime} 37^{\prime} 42^{\prime \prime}$ & $30^{\prime} 36^{\prime}$ & 2857 & 225.0 & 0.074 & 7.275 & 0.405 & Cameron et al., 1968 \\
\hline 13 & $85^{\prime} 45^{\prime} 48^{\prime \prime}$ & $08^{\prime} 42^{\prime}$ & 2695 & 221.6 & 0.085 & 7.826 & 0.394 & Cameron et al., 1968 \\
\hline 14 & $85^{\prime} 26^{\prime} 18^{\prime \prime}$ & $04^{\prime} 42^{\prime}$ & 2672 & 224.3 & 0.066 & 8.513 & 0.394 & Cameron et al., 1968 \\
\hline 15 & $85^{\prime} 10^{\prime} 12^{\prime \prime}$ & $01^{\prime} 48^{\prime}$ & 2628 & 223.4 & 0.093 & 8.159 & 0.393 & Cameron et al., 1968 \\
\hline 16 & $85^{\prime} 13^{\prime} 18^{\prime \prime}$ & $07^{\prime} 42^{\prime}$ & 2679 & 223.8 & 0.049 & 8.384 & 0.369 & Cameron et al., 1968 \\
\hline 17 & $85^{\prime} 10^{\prime} 48^{\prime \prime}$ & $13^{\prime} 12^{\prime}$ & 2688 & 223.4 & 0.053 & 8.036 & 0.365 & Cameron et al., 1968 \\
\hline 18 & $84^{\prime} 58^{\prime} 06^{\prime \prime}$ & $17^{\prime} 54^{\prime}$ & 2676 & 224.4 & 0.078 & 7.426 & 0.385 & Cameron et al., 1968 \\
\hline 19 & $85^{\prime} 50^{\prime} 48^{\prime \prime}$ & $21^{\prime} 48^{\prime}$ & 2683 & 224.6 & 0.064 & 7.847 & 0.375 & Cameron et al., 1968 \\
\hline 20 & $84^{\prime} 41^{\prime} 48^{\prime \prime}$ & $26^{\prime} 00$ & 2792 & 226.5 & 0.075 & 6.799 & 0.397 & Cameron et al., 1968 \\
\hline 21 & $84^{\prime} 31^{\prime} 42^{\prime \prime}$ & $30^{\prime} 06^{\prime}$ & 2872 & 227.0 & 0.060 & 7.178 & 0.385 & Cameron et al., 1968 \\
\hline 22 & $84^{\prime} 22^{\prime} 12^{\prime \prime}$ & $33^{\prime} 54^{\prime}$ & 3046 & 226.0 & 0.062 & 7.09 & 0.392 & Cameron et al., 1968 \\
\hline 23 & 84'10'30" & $37^{\prime} 36^{\prime}$ & 3172 & 224.4 & 0.133 & 7.414 & 0.397 & Cameron et al., 1968 \\
\hline 24 & $83^{\prime} 52^{\prime} 42^{\prime \prime}$ & $41^{\prime} 18^{\prime}$ & 3314 & 221.7 & $? ?$ & 7.821 & 0.392 & Cameron et al., 1968 \\
\hline 25 & $83^{\prime} 20^{\prime}$ & $44^{\prime} 33^{\prime}$ & 3397 & 220.5 & 0.067 & 8.081 & 0.375 & Cameron et al., 1968 \\
\hline 26 & $83^{\prime} 10^{\prime} 30^{\prime \prime}$ & $47^{\prime} 28^{\prime}$ & 3497 & 219.2 & 0.057 & 7.6 & 0.382 & Cameron et al., 1968 \\
\hline 27 & $82^{\prime} 50^{\prime} 12^{\prime \prime}$ & $50^{\prime} 31^{\prime}$ & 3577 & 217.6 & 0.066 & 7.3 & 0.371 & Cameron et al., 1968 \\
\hline 28 & $82^{\prime} 27^{\prime} 12^{\prime \prime}$ & $52^{\prime} 52^{\prime}$ & 3659 & 216.5 & 0.065 & 6.8 & 0.363 & Cameron et al., 1968 \\
\hline 29 & $82^{\prime} 06^{\prime} 47^{\prime \prime}$ & $55^{\prime} 02^{\prime} 02^{\prime \prime}$ & 3718 & 215.7 & 0.061 & 6.8 & 0.364 & Cameron et al., 1968 \\
\hline
\end{tabular}


Acknowledgements. We would like to thank J.-M. Barnola for comments on an earlier version of this manuscript. The meteorological model data (RACMO) and accumulation data were prepared in collaboration with David Vaughan, for which we are very grateful. C. Reijmer we would like to thank for her help with this the RACMO data set. Words of gratitude should go to R. Mulvaney, W. Sturges, D. Etheridge, J. Butler and M. Battle for sharing their firn air data and density profiles from the firn air analyses performed in Antarctica and Greenland.

This work is a contribution to the European Project for Ice Coring in Antarctica (EPICA), a joint European Science Foundation (ESF)/EC scientific program, funded by the European Commission and by national contributions from Belgium, Denmark, France, Germany, Italy, The Netherlands, Norway, Sweden, Switzerland and the United Kingdom. This is EPICA Publication No. 109. Additional funding was obtained from the Netherlands AntArctic Programme of the Netherlands Organisation for Scientific Research (NWO) and the budget from COACH (Cooperation on Oceanic, Atmospheric and Climate Change Studies), a collaboration of the Netherlands Centre for Climate Research (KNMI, IMAU, RIVM), the Max Planck Institut für Meteorologie in Hamburg and the Max Planck Institut für Chemie in Mainz, Germany.

Edited by: W. T. Sturges

\section{References}

Arnaud, L., Lipenkov, V. Y., Barnola, J.-M., Gay, M., and Duval, P.: Modelling of the densification of polar firn: characterization of the snow-firn transition, Ann. Glaciol., 26, 39-44, 1998.

Aydin, M., Saltzman, E. S., de Bruyn, W., J., Montzka, S. A., Butler, J. H., and

Barnola, J.-M., Pimienta, P., Raynaud, D., and Korotkevich, Y. S.: $\mathrm{CO}_{2}$-climate relationship as deduced from the Vostok ice core: a re-evaluation of the air dating, Tellus, 43(B), 83-90, 1991.

Bender, M. L., Sowers, T., Barnola, J.-M., and Chappellaz, J.: Changes in the $\mathrm{O}_{2} / \mathrm{N}_{2}$ ratio of the atmosphere during recent decades reflected in the composition of air in the firn at Vostok Station, Antarctica, Geophys. Res. Lett, 21(3), 189-192, 1994

Butler, J. H., Battle, M., Bender, M. L., Montzka, S. A., Clarke, A. D., Saltzman, E. S., Sucher, C. M., Severinghaus, J. P., and Elkins J. W.: A record of atmospheric halocarbons during the twentieth century from polar firn air, Nature, 399, 749-755, 1999.

Cameron, R. L., Picciotto E., Kane, H. S., and Gliozzi, J.: Glaciology of the Queen Maud Land Traverse, 1964-1965 South PolePole of Relative inaccessibility, Institute of polar studies, report no. 23, Ohio, 1968.

Craven, M. and Allison, I.: Firnification and the effects of windpacking on Antarctic snow, Ann. Glaciol., 27, 239-245, 1998.

Cunningham, R. E. and Williams, R. J. J.: Diffusion in gases and porous media, Chapter 4, Plenum, New York and London, 1980.

Fabre, A., Barnola, J.-M., Arnaud, L., and Chappellaz, J.: Determination of gas diffusivity in polar firn: comparison between experimental measurements and inverse modeling, Geophys. Res. Lett., 27, 4, 557-560, 2000.

Gow, A. J.: Deep core studies of the accumulation and densification of snow at Byrd Station and Little America V, Antarctica. U.S.
Cold Regions Research and Engineering Laboratory, Research Report 197, 1968.

Herron, M. and Langway Jr., C.: Firn densification: An empirical model, J. Glaciol., 25, 373-385, 1980.

Kameda, T., Shoji, H., Kawada, K., Watanabe, O., and Clausen, H. B.: An empirical relation between overburden pressure and firn density, Ann. Glaciol., 20, 87-94, 1994.

Kaspers, K. A., van de Wal, R. S. W., de Gouw, J. A., Hofstede, C. M., van den Broeke, M. R., van der Veen, C., Neubert, R. E. M., Meijer, H. A. J., Brenninkmeijer, C. A. M., Karlöf, L., and Winther, J.-G.: Analyses of firn gas samples from Dronning Maud Land, Antarctica. Part 1: Study of non-methane hydrocarbons and methyl chloride, J. Geophys. Res., 2003jd003950, 2004.

Martinerie, P., Lipenkov, V. Y., Raynaud, D., Chappellaz, J., Barkov, N. I., and Lorius, C.: Air content paleo record in the Vostok ice core (Antarctica): A mixed record of climatic and glaciological parameters, J. Geophys. Res., 99 , D5, 10 565-10 576, 1994.

Neftel, A., Moor, E., Oeschger, H., and Stauffer, B.: Evidence from polar ice cores for the increase in atmospheric $\mathrm{CO}_{2}$ in the past two centuries, Nature, 315, 45-47, 1985.

Rommelaere, V., Arnaud, L., and Barnola, J.-M.: Reconstructing recent atmospheric trace gas concentrations from polar firn and bubbly ice data by inverse methods, J. Geophys. Res., 102, D25, 30 069-30 083, 1997.

Schwander, J.: The transformation of snow to ice and occlusion of gases, in The Environmental Record in Glaciers and Ice Sheets, edited by Langway, H. O. and C., John Wiley \& Sons, Inc., New York, 53-67, 1989.

Schwander, J., Stauffer, B., and Sigg, A.: Air mixing in firn and the age of the air at pore close-off, Ann. Glaciol., 10, 141-145, 1988.

Schwander, J., Barnola, J.-M., Andrié, C., Leuenberger, M., Ludin, A., Raynaud, D., and Stauffer, B.: The age of the air in the firn and ice at Summit, Greenland, J. Geophys. Res., 98, D2, 28312838, 1993.

Spahni, R., Schwander, J., Flückiger, J., Stauffer, B., Chappellaz, J., and Raynaund, D.: The attenuation of fast atmospheric $\mathrm{CH}_{4}$ variations recorded in polar ice cores, Geophys. Res. Lett., 30, 11, 1571, doi:10.1029/2003GL017093, 2003.

Spencer, M. K., Alley, R. B., and Creyts, T. T.: Preliminary firndensification model with 38-site dataset, J. Glaciol., 159, 671676, 2001.

Sturges, W. T., McIntyre, H. P., Penkett, S. A., Chappellaz, J., Barnola, J.-M., Mulvaney, R., Atlas, E., and Stroud, V.: Methyl bromide, other brominated methanes, and methyl iodide in polar firn air, J. Geophys. Res., 106, D2, 1595-1606, 2001.

Trudinger, C. M., Enting, I. G., Etheridge, D. M., Francey, R. J., Levchenko, V. A., and Steele, L. P.: Modeling air movement and bubble trapping in firn, J. Geophys. Res., 102, D6, 6747-6763, 1997.

Trudinger, C. M., Etheridge, D. M., Rayner, P. J., Enting, I. G., Sturrock, G. A., and Langenfelds, R. L.: Reconstructing atmospheric histories from measurements of air composition in firn., J. Geophys. Res., 107, D24, 2002.

Van den Broeke, M. R., Winther, J.-G., Isaksson, E., Pinglot, J. F., Karlof, L., Eiken, T., and Conrads, L.: Climate variables along a traverse line in Dronning Maud Land, East Antarctica, J. Glaciol., 45, 150, 295-302, 1999. 
Van Lipzig, N. P. M., van Meijgaard, E., and Oerlemans, J.: Evaluation of a regional atmospheric model using measurements of surface heat exchange processes from a site in Antarctica, Mon. Wea. Rev., 127, 9, 1994-2011, 1999.

Van Lipzig, N. P. M., van Meijgaard, E., and Oerlemans, J.: The spatial and temporal variability of the surface mass balance in
Antarctica: results from a regional climate model, Int. J. Climatol., 22, 1197-1217, 2002

Vaughan, D. G., Bamber, J. L., Giovinetto, M., Russell, J., and Cooper, A. P. R.: Reassessment of net surface mass balance in Antarctica, J. Climate, 12, 4, 933-946, 1999. 